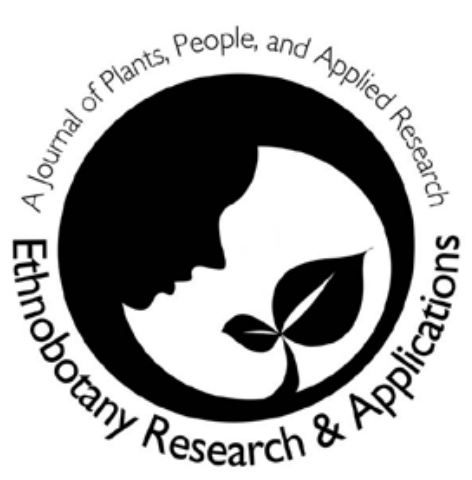

\title{
Traditional Botanical Knowledge of the Plain Mennonites: Time, change, and knowledge transitions
}

\author{
Adam Brown, K.W. Bridges, and Will C. McClatchey
}

\section{Research}

\begin{abstract}
This study quantifies the culinary and medicinal botanical knowledge of the Old Order or Plain Mennonites in eastern Pennsylvania, a religious group which chooses to reject certain elements of modern technology. The study tests the hypothesis that time, geography, and degree of religious conservatism impact the retention of botanical knowledge. Historical cookbooks and medical texts were combined with data from modern interviews to identify useful plants from a number of locations and times, allowing trends in botanical knowledge to be identified. The dominant pattern presented by these data is one of overall cultural conservatism, and the literate nature of this culture is the best explanatory factor for this pattern.
\end{abstract}

\section{Background}

One of the frequently cited reasons for conducting ethnobotanical work is the need to record localized botanical and ecological knowledge, often a disappearing intellectual resource (Ramirez 2007). This study addresses the question of botanical knowledge change by using a combination of historical and modern data points to test the hypothesis that time, geography, and degree of religious conservatism impact the evolution of this knowledge in the Plain Mennonite community of eastern Pennsylvania, U.S.A., and to evaluate the degree of change that has occurred over the last two centuries.

The work presented here is based on several previous studies that utilize historical ethnobotanical sources. Buenz et al. (2004) pointed out the potential for the use of historical sources and provided procedures for data mining of historical sources. They suggest that researchers examine digitized historical information when looking for medicinal phytochemicals in order to narrow down the universe of potential plant species for examination. They did this by searching for species that are used for similar purposes in a large number of cultures, ruling out those not widely reported as being medicinal.

There are several examples of studies with a cultural evolutionary component that used historical documentation in the experimental design. Heinrich et al. (2006) reviewed three such studies, examining similarities between the uses of rosemary in the Old World and its uses in Mexico and Guatemala. They found conceptual links, although the uses were not identical. Kufer et al. (2005) compared a modern plant list from the Ch'orti' Maya in Guatemala which had been developed through interviews, to a historical plant list available from the same culture that was compiled in the 1930s. The Kufer et al. (2005) study used quantitative methods applied to the interview data to compare the relative importance of plants which appear in both lists to those which appear in the interviews only. They found that those appearing in both are consistently more important to the culture. Nguyen (2007) compared

\section{Correspondence}

Adam Brown, Department of Chemistry \& Biochemistry, University of North Carolina, Greensboro, North Carolina, U.S.A. brownsbotany@gmail.com

K.W. Bridges, Botany Department, University of Hawai i at Mānoa, Honolulu, Hawai i, U.S.A.

W.C. McClatchey, Botanical Research Institute of Texas, Fort Worth, Texas, U.S.A.

Ethnobotany Research \& Applications 12:571-596 (2014)

Published: 24 November 2014 
the structure of a culinary recipe, which has high cultural relevance both in Vietnam and among Vietnamese immigrants to the United States, by using multiple texts. She analyzed a variety of cookbooks with different origins and compared the botanical contents for this recipe. The key finding was that while the cookbooks from the United States and Vietnam had some differences in species, the functions performed by those species in determining the aesthetic characteristics of the dish remained relatively stable. Her study showed the utility of combining multiple text sources when analyzing spatial change in knowledge.

Leonti et al. (2009, 2010) and Leonti (2011) tested the hypothesis that written sources influence observed ethnobotanical knowledge in modern literate societies. The key assertions from these papers include the observation that written sources can: 1) add to the conservatism of folk medicinal systems by making a body of knowledge permanently accessible, 2) increase the speed of change by making information available that would not have been present if the culture was limited to face-toface interactions as the sole means of information transfer, 3) lead to the insertion of new plants and new uses for known plants into folk medicinal traditions through understandings drawn from modern biomedical publications (the authors use the example of the use of garlic for cardiac health), and 4) flood a population with herbals containing widespread knowledge leading to the homogenization of folk medicinal knowledge.

The Plain Mennonites of eastern Pennsylvania represent a largely agrarian, religious community that has retained a connection to its historical culture in spite of its existence in an area surrounded by rapidly changing cultures of the U.S.A. Because the Mennonites have a long tradition of literacy, their historical records provide a good opportunity for an ethnobotanical study which compares historical practices to modern observations. This would not be possible in more isolated cultures that only recently received a written language or modern literate cultures that lack continuity with their past traditions and historical botanical knowledge.

\section{Cultural background of the Plain Mennonite community}

The Mennonite people are a subset of a larger religious group which is often referred to with the umbrella term "Anabaptist." The Anabaptist movement has its roots in the early 1500 s, as an outgrowth of earlier reformation movements such as those lead by Martin Luther and Huldrych Zwingli. Believing that none of the parallel movements went far enough in rejection of Roman Catholicism, Anabaptism emerged by the mid-1500s as a separate sect, characterized by three dominant tenants: adult baptism; freedom of conscience and the belief that no human government or ecclesiastical body is qualified to dictate the relationship between man and God; and nonresis- tance or complete pacifism. The first two of these central beliefs alienated the Anabaptists from state church organizations, and the third from often-quarreling European states themselves. On this account, the state and ecclesiastical (both Catholic and Protestant) hierarchies throughout Europe combined forces and subjected the Anabaptists to every form of torture and persecution available in the Middle Ages - a considerable list (Smith 1941). By the end of the 1600s, the Anabaptist movement split into several large sub-groups. Some of the largest and most well-known are the Mennonite, Amish, and Hutterite sects. This period of persecution also caused an Anabaptist diaspora. The Anabaptists have long been recognized, even by feudal landlords, to be excellent agriculturists (Smith 1941). Some of notable Anabaptist improvements to agriculture include introducing forage production, the use of lime to improve soils, and other improvements in fertilizer management (Correll 1991). Anabaptist farmers were among the first in Europe to accept the potato (Correll 1991). The result of their advanced farming skills was that there were always regions in Europe where appreciative landowners held sufficient power to shelter them. One such refuge was the Palatinate/Rhineland region of western Germany, from which the first Anabaptist immigrants came to Pennsylvania in the late 1600s (Smith 1941, Weaver 1982).

The first, small Anabaptist migration to the New World began in 1683. They founded the first lasting Anabaptist colony, Germantown, in the greater Philadelphia area of southeastern Pennsylvania (see map in Figure 1). This immigration trend accelerated from a trickle to a flood through the early 1700 s and did not slow until 1727 when British authorities changed their immigration policies. The early arrivals included Mennonites, other German Protestant groups, and English Quakers. The Amish came late in this period. These people quickly formed a composite culture and common language (the local Germanic dialect of the Palatinate combined with elements of English), both locally referred to as "Pennsylvania German" and "Pennsylvania Dutch." These early immigrants settled in the region of Pennsylvania southeast of a long ridge called the "Blue Mountain." This was the edge of the American frontier prior to the French and Indian war. After the war, Anabaptist populations expanded northwards into the Ridge and Valley Region of Pennsylvania. Both of these regions possess excellent farmland to which these agricultural traditions were easily adapted. Since that time, the Pennsylvania Mennonites have spread far beyond the original core area and more emigrations out of Europe have occurred. Now, there are Anabaptist towns found throughout North and South America (Smith 1941).

The Mennonite sect is not at all homogeneous. In keeping with the tradition of freedom of conscience, whenever there was a difference in opinion that could not be reconciled, the conflicting groups simply established new congregations. A number of these developed into large follow- 


\section{Brown et al. - Traditional Botanical Knowledge of the Plain Mennonites: Time, change, and knowledge transitions}

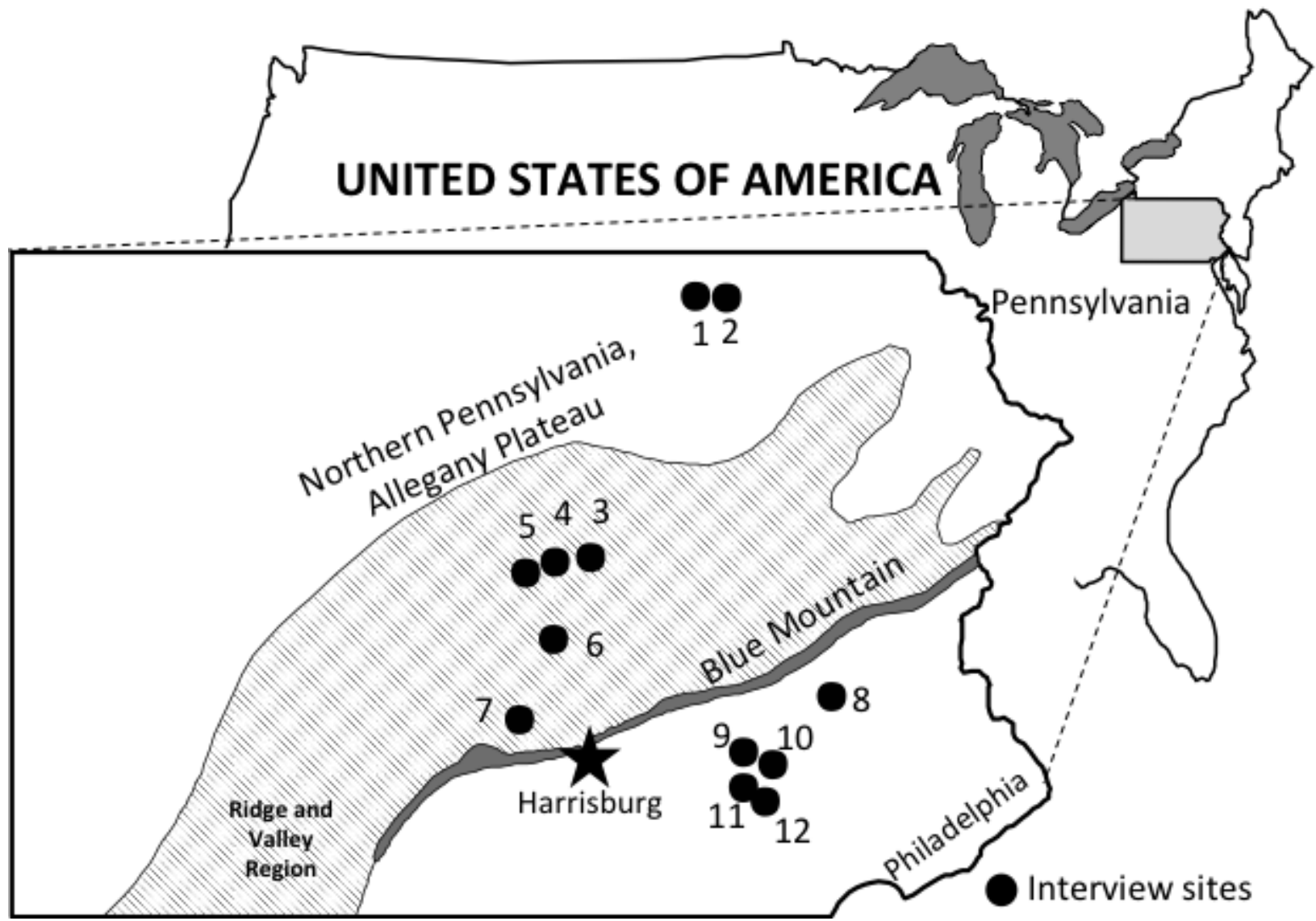

Figure 1. Pennsylvania showing interview locations. Locations of the nearest town to each interview, within the study area of eastern Pennsylvania: 1) Rome, one interview; 2) Potterville, three interviews; 3) Lewisburg, one interview; 4) Vicksburg, four interviews; 5) Mifflinburg, one interview; 6) Mt. Pleasant Mills, one interview; 7) Loysville, two interviews; 8) Kutztown, one interview; 9) Denver, one interviews; 10) Bowmansville, one interview; 11) Ephrata, three interviews; 12) New Holland, one interview.

ings while others failed to survive past a handful of founding families. Groups of like-minded congregations form "Conferences." In 1860, many of these various sects were brought together in a loose union under a body named the "General Conference of the Mennonite Church of North America." The General Conference is not a traditional ecclesiastical system of governance, which would never be tolerated, but is an advisory body which allows any of the subgroups who choose this structure to pool resources for missions, peace, and relief work in many regions of the world (Smith 1941).

Relative religious conservatism is difficult to pin down. However, within these communities, some sects are perceived as more conservative (or, as it would be stated locally, "more plain") than others. A relative conservative ranking of Anabaptist sub-groups encountered in this study follows, from most to least plain (all personal observations of the lead author): Staufer Conference (allow no modern convenience in any setting), Groffdale Conference (allow modern equipment in a work setting but not in a home setting), Weverland conference (allow modern conveniences as long as they are "plain", for example, cars may not have chrome parts), and lastly the Mid Atlantic Fellowship Mennonites, who generally accept modernity but maintain "plain" (traditional) dress. The specific nuances of what is allowable and what is not varies even within sub-groups. A similar range of sub-groups exist within the Amish communities, neither the Amish nor the Mennonites are homogeneous in any cultural attribute. The importance of the Pennsylvania German dialect tends to loosely follow the trends of cultural conservatism, often being more important in more plain communities.

There is evidence for direct contact between the early Pennsylvania Dutch settlers (Mennonites and Amish) and Native Americans of the Delaware tribes. Smith (1941) notes that the children of Anabaptist communities played with the Delaware children. A diary-style notebook kept by Benjamin Herr (c.1808-1829) (Herr et al. 2007) includes many lists of plants and animals, ranging from simple catalogs to specific observations. One such observation was 
of an "Indian doctor" described as a "half-breed aboriginal and a botanic physician" gathering plants. Mr. Herr was not impressed with the quality of this individual's medical care (his reasoning for this is not stated), however, he goes out of his way to record the plants that he saw being collected - "snake-root (black and Virginia), angelica, wintergreen, Indian turnip, blood root, centaury, sassafras, gentian, benzoin, and pennyroyal" (Herr et al. 2007).

The Mennonite people have been able to maintain their traditional culture in the modern world. This is a highly literate society, having been literate from their beginnings in the Reformation. By adulthood, most of the conservative Mennonites in Pennsylvania are bilingual, fluent in English and Pennsylvania Dutch. Many can also read and write High German, though it is not spoken (Smith 1941, personal observation).

There are several healing systems in the Pennsylvania Dutch community including self-reliant home medicine and modern medicine (personal observations). Historically there was also a faith-healing system called brouchen or powwow healing. Kreibel (2008) reports on modern continuation of the practice in more secular branches of Pennsylvania German culture but the lead author saw no evidence of this system's continued existence, except a few opinions of it being a distasteful practice, and a few distant memories of now-deceased family members encountering the practice in one or more ways.

\section{Methods}

\section{Interview data}

The interview portion of this study appraised the current botanical knowledge relating to the culinary practices and medicinal plant usage of the Plain Mennonites of eastern Pennsylvania. After obtaining approval from the University of Hawai i at Manoa Institutional Review Board, semistructured interviews were held with volunteers recruited via snowball sampling (Bernard 2002). Each interview was separated into three questions about three categories of plants-wild collected plants, cultivated plants, and plants obtained via commerce. In each interview section, a series of prompts was used to elicit free-listing (Bernard 2002). These were berries and fruits, nuts, greens, roots and tubers, flowers, grasses/grains/cereals, teas, vegetables, herbs and spices, sweeteners, plus the prompt "medicinal plants," which was described to the participant as anything eaten, made into a tea, or used as a salve for medicinal or health-related purposes. These interviews were conducted in English. When a medicinal plant was named, specific usage information was requested. At the completion of each section of the interview, the list of plants was read back to the participant, who was then asked if a Pennsylvania German name existed for each and if any varieties could be named. Basic demographic information was also recorded. Each informant was given a copy of the interview notes so that he or she would have an opportunity to comment, either in person or through the mail. Completeness of sample was evaluated by the use of species accumulation curves; arctan functions (Larson et al. 2001) were fit to the data, and the horizontal limit was used as the predictions of maximum botanical knowledge. The number of ethnotaxa recorded at the end of the study was then compared to this predicted maximum. These data were analyzed using cluster analysis in the software PAST (Hammer et al. 2001). The Lancaster Mennonite Historical Society (www.Imhs.org/), located in Lancaster, Pennsylvania, has archived transcribed copies of the information collected during these interviews (coded by interview number) to preserve the raw data used in this study for future examination by other researchers, as well as to return the information collected to the community studied.

\section{Cookbook and medicinal text analysis}

The cookbook analysis portion of this study was adapted from the methods presented in Nguyen (2007). Cookbook sampling included searching publicly available book collections in libraries and historical societies, as well as the purchase of books through Internet-based book sellers and Internet-based auctions. As some sources are reprints of older data, the citation date and the date in which the information first appeared in print are not necessarily the same. The data contained in these books were entered into a database as the presence or absence of a given plant in a given recipe. If the plant was present, the entry in that data cell was "1"; if absent a "0". The analysis consisted of calculating the probability of a given plant appearing in a given cookbook as the total number of recipes containing that taxon divided by the total number of recipes. The cookbooks were compared based on these probability data using principal components analysis in PAST (Hammer et al. 2001).

Medicinal texts were analyzed similarly to the cookbooks, with one key difference. Since the medicinal texts used were far less repetitive than the culinary sources, no attempt was made to tally mentions of plants in individual recipes. Instead, the presence or absence was recorded at the level of the book, with presence recorded as a " 1 ", and absence as a " 0 ". The resulting data table was then analyzed using cluster analysis and the Jaccard similarity index using the same software and procedure as for the culinary data. The books were selected to represent primarily the Pennsylvania German culture but also include sources selected to represent non-European pharmacopeias that can be assigned to surrounding cultures with which the Anabaptists had contact-the indigenous Delaware tribes (Moerman 2006). 


\section{Brown et al. - Traditional Botanical Knowledge of the Plain Mennonites: Time, change, and knowledge transitions}

\section{Results}

\section{Interview data}

A total of twenty interviews were conducted between May, 2008 and May 2009 with the majority taking place during the winter and early spring months. Thirty-five participants (over the age of 18) took part in these interviews, including 15 men and 20 women. In several cases parents, who were the primary informants, involved their children in the interview process, using it as a teaching opportunity. In two of these cases the children, under their parent's supervision, contributed substantially to the data collected in the interviews. Interviews were conducted in 4 sub-groups of the Mennonite community - the Groffdale Conference (9 interviews), Weaverland Conference
(6 interviews), Stauffer Conference (1 interview), and the Mid Atlantic Fellowship Mennonites (4 interviews). Interviews were located in twelve towns from the three major geographical regions of eastern Pennsylvania (Figure 1) - the Alleghany Plateau in the north, the Ridge and Valley region in the center of the state, and southeastern Pennsylvania which is a mixture of several smaller geological regions (the largest being the Great Valley and Piedmont regions) (Van Diver 1990). No self-identifying herbal medicine specialists/practitioners were found in the course of this study, though one informant sold essential oils for part of the family income. The interviews produced a total of 245 ethnotaxa, including 5 mixed categories (for example, "mixed seasonings"). The total included 220 which had a culinary use and 62 with some medicinal use. The species accumulation curve (Figure 2) shows diminishing returns. In order to produce numerical data suit-

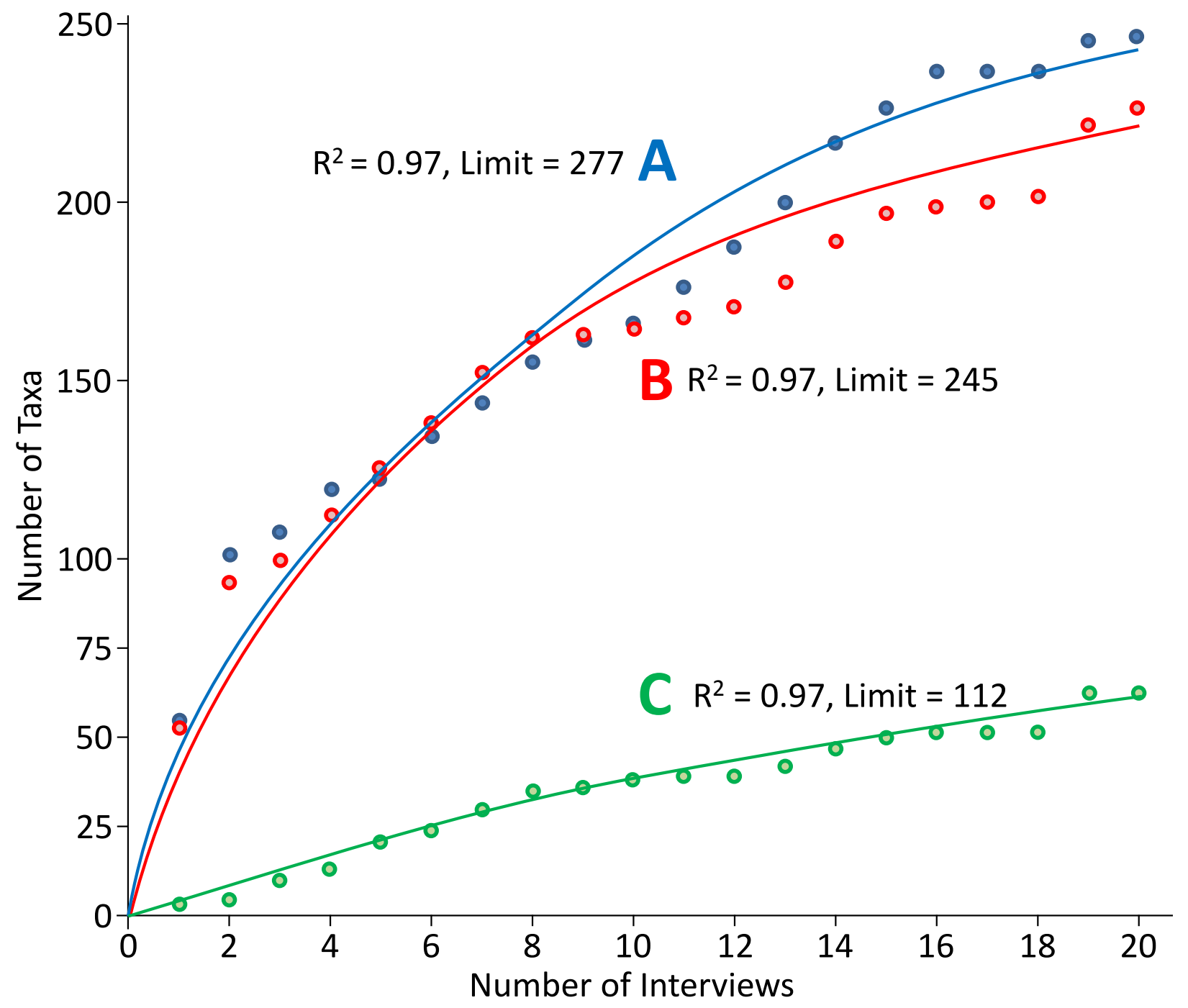

Figure 2. Species accumulation curves fitted with arctangent functions showing the accumulation of $(A)$ all taxa recorded, (B) culinary taxa, and (C) medicinal taxa. Data are from interviews with Plain Mennonites in eastern Pennsylvania, U.S.A. 


\begin{tabular}{|l|c|c|c|c|c|c|c|c|c|c|c|c|c|c|c|c|c|c|c|c|}
\hline Region & N & N & N & N & R & R & R & E & R & R & E & E & E & R & E & E & E & R & R & R \\
\hline Sect & M & M & M & M & G & G & W & W & G & G & G & G & W & S & G & W & W & G & W & G \\
\hline Interview & 18 & 19 & 17 & 20 & 4 & 5 & 6 & 7 & 8 & 9 & 10 & 11 & 12 & 13 & 14 & 15 & 16 & 3 & 2 & 1 \\
\hline \multicolumn{10}{|l|}{} & \\
\hline
\end{tabular}

Figure 3. Cluster analysis (Jaccard's similarity method, paired grouping; coefficient of correlation $=0.978$ ) results for interviews of Plain Mennonites in eastern Pennsylvania, U.S.A. Sect affiliations (and their abbreviations from least to most conservative: Groffdale Conference (G), Mid Atlantic Fellowship Mennonites (M), Staufer Conference (S), Weaverland Conference (W)). Regions: northern Pennsylvania (N), southeastern Pennsylvania (E), ridge and valley province (R).

able for multivariate analysis, a series of 14 tallies were produced (Appendix 1). Cluster analysis was used to produce dendrograms showing the relationship between interviews, the Jaccard similarity index with a paired-group method (Figure 3). Results from this cluster analysis show that the interviews from the Ridge and Valley province and southeastern Pennsylvania are quite similar to each other and than these are quite distinct from the two groupings into which the interviews from northern Pennsylvania fall. Qualitatively, the most outstanding differences between the northern and southern data points are an increased dependence on commerce and the complete or near complete absence of the Pennsylvania Dutch language, which can be seen in the eighth line of Appendix 1. Appendices 2 and 3 shows the ethnotaxa mentioned in each interview.

\section{Historical Data}

A total of 10 cookbooks (Table 1) were evaluated in this study. These cookbooks contained 171 plant ethnotaxa and 8 categories in which mixed, prepared products were used. The scatter plot generated from these data using

Table 1. Historical and modern cookbooks of Plain Mennonites in eastern Pennsylvania, U.S.A.

\begin{tabular}{|c|c|c|c|c|}
\hline Books & Cultural connections & Notes & $\begin{array}{l}\text { Number } \\
\text { of recipes }\end{array}$ & $\begin{array}{l}\text { Mean plants } \\
\text { per recipe }\end{array}$ \\
\hline Brendle 1973 & Mennonite & $\begin{array}{l}\text { "Weaverland Mennonite Cookbook." } \\
\text { A church-produced cookbook, dishes } \\
\text { presented at two potlucks, one 1973, } \\
\text { other } 1974 \text {. }\end{array}$ & 135 & 4.71 \\
\hline Collester 1992 & Amish & $\begin{array}{l}\text { A newer edition of a book originally } \\
\text { copyrighted in } 1980 \text {. }\end{array}$ & 63 & 5.54 \\
\hline Frederick 1946 & $\begin{array}{l}\text { Pennsylvania German, sect } \\
\text { not specifically assignable }\end{array}$ & $\begin{array}{l}\text { Written from the etic perspective with } \\
\text { the stated agenda of preserving } \\
\text { regional cookery. }\end{array}$ & 358 & 4.47 \\
\hline Kauffman 1986 & Mennonite & $\begin{array}{l}\text { Reprint of an earlier notebook, } \\
\text { Amanda Kauffman lived 1888-1934. }\end{array}$ & 150 & 3.04 \\
\hline Lustwig 1967 & $\begin{array}{l}\text { Pennsylvania German, sect } \\
\text { not specifically assignable }\end{array}$ & $\begin{array}{l}\text { Compiled by the Culinary Arts Press, } \\
\text { published in Reading, Pennsylvania. }\end{array}$ & 248 & 4.21 \\
\hline Miller 1984 & Amish & $\begin{array}{l}\text { Contains recipes from Pennsylvania } \\
\text { and across the U.S.A., including the } \\
\text { western states. }\end{array}$ & 728 & 4.50 \\
\hline Vollmer 1867 & $\begin{array}{l}\text { Cultural identity not } \\
\text { assignable, though it } \\
\text { appears the Pennsylvania } \\
\text { German cultural complex } \\
\text { was a portion of the } \\
\text { targeted audience }\end{array}$ & $\begin{array}{l}\text { Printed in both English and German, } \\
\text { on opposing pages. The English } \\
\text { translation was produced by J.C. } \\
\text { Oehlschlager apparently at time } \\
\text { of publication. }\end{array}$ & 555 & 3.93 \\
\hline
\end{tabular}



Brown et al. - Traditional Botanical Knowledge of the Plain Mennonites:
Time, change, and knowledge transitions

\begin{tabular}{|l|l|l|c|c|}
\hline Books & Cultural connections & Notes & $\begin{array}{c}\text { Number } \\
\text { of recipes }\end{array}$ & $\begin{array}{c}\text { Mean plants } \\
\text { per recipe }\end{array}$ \\
\hline Walton 2005 & $\begin{array}{l}\text { Pennsylvania German, } \\
\text { including Mennonite } \\
\text { knowledge }\end{array}$ & $\begin{array}{l}\text { A compilation of recipes from } \\
\text { the 1880s to 1950s. Likely to be } \\
\text { Mennonite, but specific affiliation } \\
\text { of many recipes unknown. }\end{array}$ & 394 & 3.44 \\
\hline Weaver 1983 & $\begin{array}{l}\text { Pennsylvania German, sect } \\
\text { not specifically assignable }\end{array}$ & $\begin{array}{l}\text { A compilation and translation of } \\
\text { recipes originally printed in German } \\
\text { spanning the time frame from } \\
1791-1851, \text { with most from 1848. }\end{array}$ & 155 & 3.43 \\
\hline $\begin{array}{l}\text { Woman's } \\
\text { Sissionary }\end{array}$ & Meciety 1930 & $\begin{array}{l}\text { A church-produced cookbook, } \\
\text { the date is uncertain. }\end{array}$ & 405 & 3.96 \\
\hline
\end{tabular}

principle components analysis (PCA) is shown in Figure 4. The data points grouped into four categories, divided by the four quadrants of the scatter plot. Firstly, the cookbooks are separated according to date by their position along Component 1, with all books containing information exclusively dating to the 1900 s falling in quadrants $A$ and $\mathrm{B}$, and all books with information overlapping the $1800 \mathrm{~s}$ falling in quadrants $C$ and $D$. Secondly, the books of rural and urban origin are divided by their position along Component 2, with books more likely to represent rural culture falling in quadrants $\mathrm{B}$ and $\mathrm{C}$, and books representing a more urban culture (such as Books 6 and 8, Table
1) or books being produced by culinary institutes describing Pennsylvania Dutch cooking from the etic perspective (Books 2 and 4, Table 1) falling in quadrants A and D. Because the cookbooks most clearly assignable to Mennonite or Amish cultures all cluster in quadrant $\mathrm{B}$, there are no clear distinctions between the culinary botanical knowledge of these two sub-groups. As can be seen in the last column of Table 1, books representing the older culinary knowledge (those which fall in quadrants $C$ and $D$ of the PCA scatter plot) contain a mean number of plants per recipe ranging from 3.04 to 3.93 , where in the remaining (more modern) books this mean ranges from 3.96 to 5.54

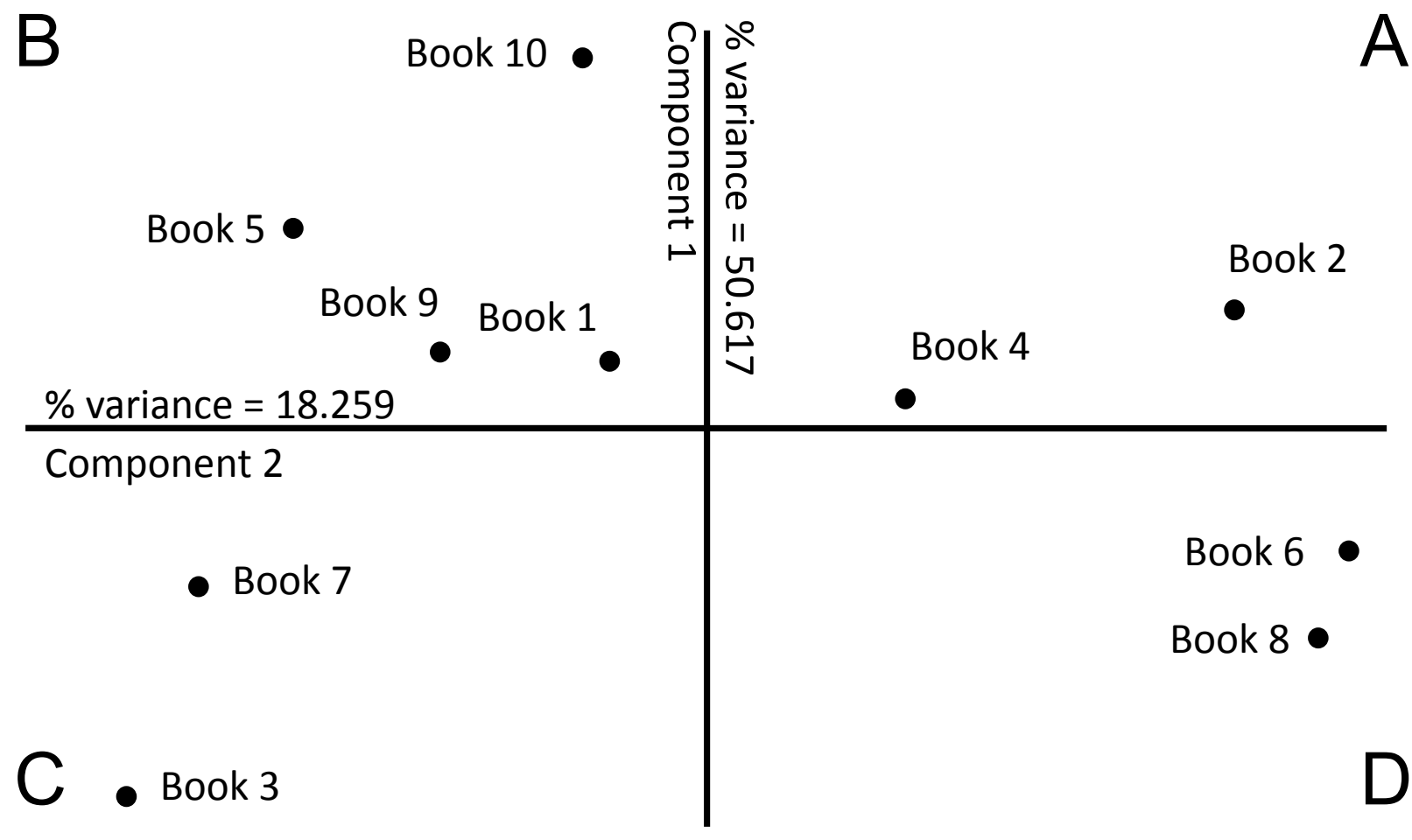

Figure 4. Principle components analysis of cookbook data extracted from ten historical and modern cookbooks of Plain Mennonites in eastern Pennsylvania, U.S.A. Books: 1. Collester 1992, 2. Frederick 1946, 3. Kauffman 1986, 4. Lustwig 1967, 5. Miller 1984, 6. Vollmer 1867, 7. Walton 2005, 8. Weaver 1983, 9. Woman's Missionary Society 1930 , and 10. Brendle 1973. 
plant ethnotaxa per recipe, showing a significant increase in complexity of the recipes in modern time $(p=0.005$, 2-tail t-test not assuming equal variance).

Weaver (1983) primarily contains translations of recipes from a single source (with a Germanic title translating to The Handy Housewife) dating to 1848. It also contains

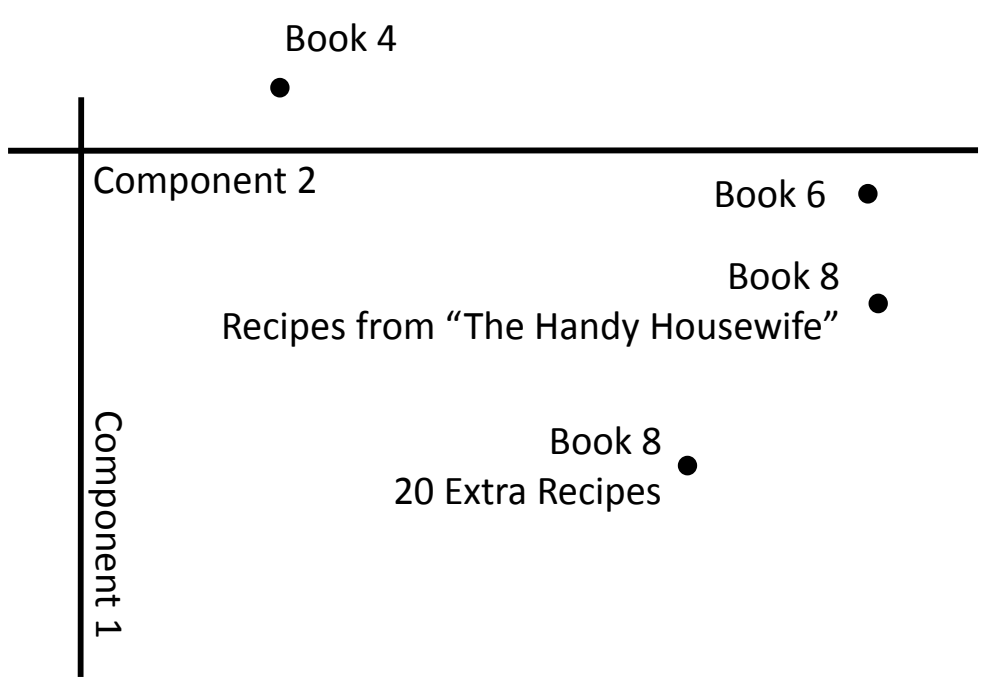

Figure 5. Principle components analysis of cookbook data illustrating the relationship between the different sources of data in Weaver (1983).
20 recipes from other sources spanning the time frame $1791-1851$. To test whether this would have thrown off the position of this data point in the PCA scatter plot, the 20 earlier recipes were separated as extra and then added in as another source with the PCA recalculated. The position of The Handy Housewife "Book 8" data did not move appreciably in relation to the remaining points, and the point representing the remaining 20 recipes also fell within quadrant $D$ (see Figure $5)$. With this result, the book has been considered as a unit in accordance with the original intent of the compiling author.

A total of 15 medical sources (Table 2) were analyzed in this study, yielding three main groupings of data shown in Figure 6. Just as with the cookbooks, several of the sources used are reprints of older information, and in these cases the citation date is not the same as the date when the information first appeared in print. The largest group of data is contained in cluster C. This grouping includes four sources of Amish origin, all of which were published in 1985 or later. The compiled medicinal data from the modern interviews dealing exclusively with the Mennonites of eastern Pennsylvania also falls within this group.

Table 2. Historical and modern medical texts used for analysis of Plain Mennonites in eastern Pennsylvania, U.S.A.

\begin{tabular}{|c|c|c|c|c|}
\hline Source & $\begin{array}{l}\text { Date first } \\
\text { produced }\end{array}$ & Cultural identity & Notes & $\begin{array}{l}\text { Medicinal } \\
\text { ethnotaxa }\end{array}$ \\
\hline Cooper 1840 & 1840 & $\begin{array}{l}\text { English language, } \\
\text { cultural affiliation } \\
\text { uncertain }\end{array}$ & $\begin{array}{l}\text { A book published in eastern Pennsylvania } \\
\text { in the English language. }\end{array}$ & 139 \\
\hline Hohman 2007 & 1820 & $\begin{array}{l}\text { Pennsylvania German, } \\
\text { sect not specifically } \\
\text { assignable }\end{array}$ & $\begin{array}{l}\text { A re-print of a widely circulated book from } \\
\text { the } 1800 \text { s containing source material } \\
\text { for the "powwow healing" tradition. }\end{array}$ & 51 \\
\hline Kauffman 1986 & $\begin{array}{l}1888- \\
1934\end{array}$ & Mennonite & $\begin{array}{l}\text { A handwritten, personal cookbook which } \\
\text { also contained a number of medicinal } \\
\text { recipes. }\end{array}$ & 65 \\
\hline Kendig et al. 2004 & $\begin{array}{l}1843- \\
1925\end{array}$ & Mennonite & $\begin{array}{l}\text { Personal notebook by a Mennonite, } \\
\text { Fannis H. Dombach Kendig, lived from } \\
\text { 1843-1925, Lancaster, Pennsylvania. }\end{array}$ & 44 \\
\hline Levine 2001 & $\begin{array}{l}1805- \\
1877\end{array}$ & Mennonite & $\begin{array}{l}\text { Personal notebook by John Reist (lived } \\
\text { 1805-1877). First remedies dated } 1822 \text {, } \\
\text { one was dated } 1867, \text { most not dated. }\end{array}$ & 32 \\
\hline McGrath 1985 & 1985 & Amish culture & Modern information. & 225 \\
\hline Miller 1985 & 1985 & Amish & $\begin{array}{l}\text { A combination of culinary and medicinal } \\
\text { recipes. }\end{array}$ & 69 \\
\hline Miller 2005 & 2000 & Amish culture & $\begin{array}{l}\text { Probably represents Midwest region of } \\
\text { North America more than Pennsylvania . }\end{array}$ & 154 \\
\hline Moerman 2006a & Various & Delaware tribes & $\begin{array}{l}\text { Collected data on the Delaware, eastern } \\
\text { tribes. }\end{array}$ & 84 \\
\hline
\end{tabular}


Brown et al. - Traditional Botanical Knowledge of the Plain Mennonites: Time, change, and knowledge transitions

\begin{tabular}{|l|l|l|l|r|}
\hline Source & $\begin{array}{l}\text { Date first } \\
\text { produced }\end{array}$ & Cultural identity & Notes & $\begin{array}{r}\text { Medicinal } \\
\text { ethnotaxa }\end{array}$ \\
\hline Moerman 2006b & Various & Delaware tribes & $\begin{array}{l}\text { Collected data on the Oklahoma } \\
\text { Delaware diaspora community }\end{array}$ & 95 \\
\hline Moerman 2006c & Various & Delaware tribes & $\begin{array}{l}\text { Collected data on the Delaware } \\
\text { Ontario diaspora community }\end{array}$ & 25 \\
\hline Quillin 1996 & 1996 & Amish culture & Modern information & 270 \\
\hline Weaver 2001 & $1762-$ & $\begin{array}{l}\text { Pennsylvania German, } \\
\text { sect not specifically } \\
\text { assignable, borrows } \\
\text { from old-world works }\end{array}$ & $\begin{array}{l}\text { A modern translation of an older } \\
\text { work, The Compendious Herbal } \\
\text { (1762-1778), first published by } \\
\text { Christopher Sauer in Philadelphia }\end{array}$ & 363 \\
\hline Wieand 1970 & 1778 (1961 & $\begin{array}{l}\text { Pennsylvania } \\
\text { German, no specific } \\
\text { sect affiliation }\end{array}$ & $\begin{array}{l}\text { A list of medicinal plants and their uses } \\
\text { collected in the mid 1900s via interviews } \\
\text { from East Central Pennsylvania }\end{array}$ & 104 \\
\hline
\end{tabular}

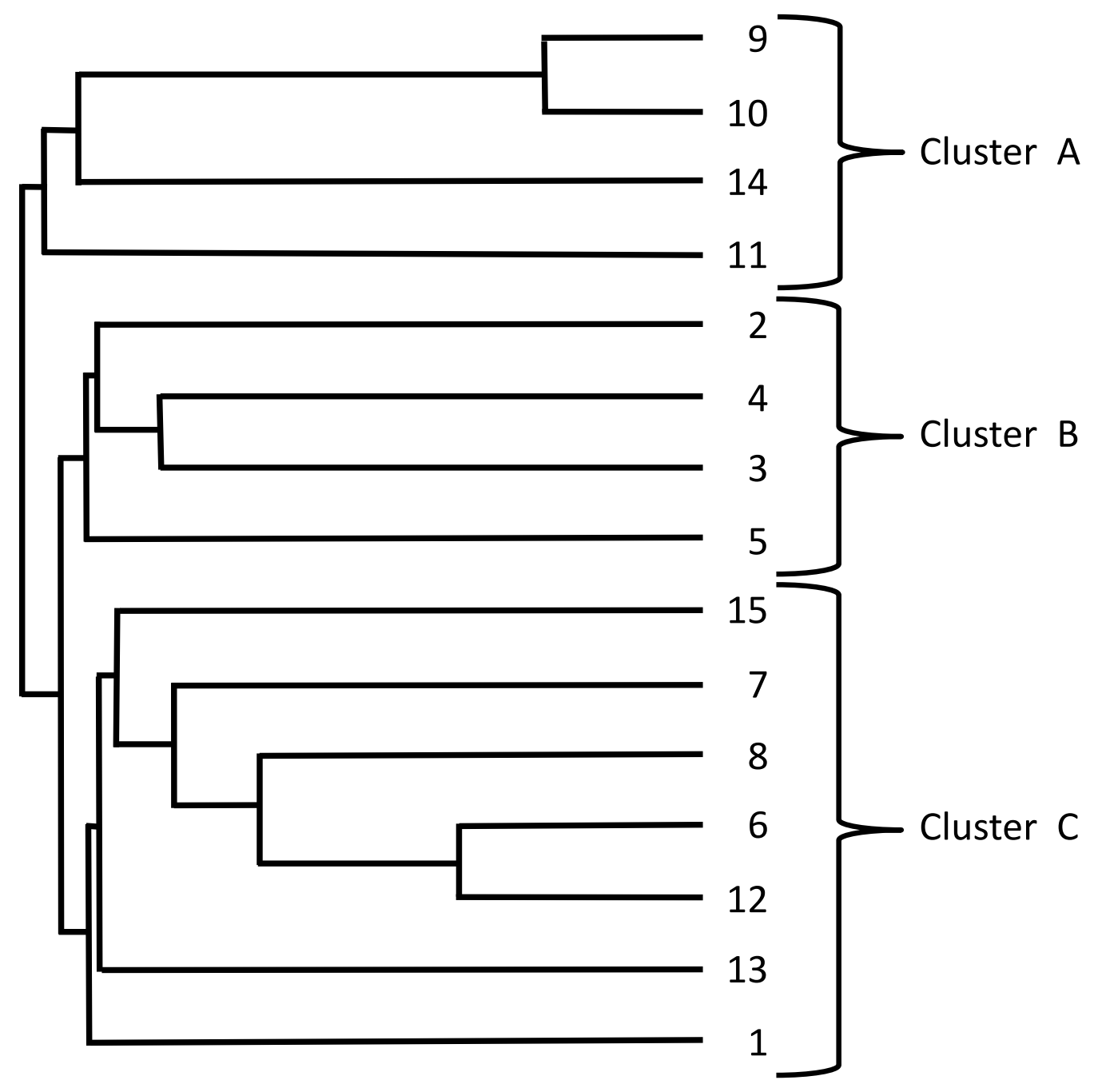

Figure 6. Cluster analysis (Jaccard's similarity method, paired grouping; coefficient of correlation $=0.929$ ) results for published medical knowledge sources (1. Cooper 1840, 2. Hohman 2007, 3. Kauffman 1986, 4. Kendig et al. 2004, 5. Levine \& Stuckey 2001, 6. McGrath 1985, 7. Miller 1985, 8. Miller 2005, 9. Moerman 2006a, 10. Moerman 2006b, 11. Moerman 2006c, 12. Quillin 1996, 13. Weaver 2001, 14. Wieand 1970) as well as a summary of the knowledge revealed in the modern interviews (15) described in Appendix 3. 
Two older sources, Weaver (2001) (Germanic, 17621778) and Cooper (1840) (English, 1840) are basal to cluster $\mathrm{C}$.

Cluster B is closely related to cluster C and contains a number of Pennsylvania German sources, all of which fall between the early 1800 s and early 1900 s. The first of these sources, Hohman (1820), is the best known source related to the powwow healing tradition. The remainder of the sources in cluster B are manuscripts, two personal notebooks, and one manuscript cookbook which contains a section of medicinal recipes.

Cluster A (Figure 6) is dominated by sources representing the pharmacopoeia of the Delaware diaspora communities and is distinct from the main body of Germanic sources. These data on Delaware medicinal plant knowledge were derived from Moerman (1998), which separated the information on the Delaware into three sub-groups, identified as Delaware, Oklahoma Delaware, and Ontario Delaware, reflecting the diaspora of the Delaware. In this cluster, the "Delaware" and "Oklahoma Delaware" data are the most closely related, with the "Ontario Delaware" more distantly related and separated by a single Germanic source, Wieand (1970).

\section{Discussion}

Three interrelated hypotheses are considered below: 1 . over time botanical knowledge changes, even in a conservative community; 2. geographical distributions reflect knowledge distributions with distance and physical barriers reducing flow of knowledge; and 3. degree of religious conservatism impacts retention of botanical knowledge.

\section{Time}

The culinary and medical data sources show that time is the dominant factor forming clusters. In both cases, the data coming from the 1900 s are distinct from earlier sources. There are only two anomalies in this pattern: Weaver (2001), a reprint and translation of information which first appeared in the mid 1700s and Cooper (1840), an English language source from southern Pennsylvania. Both group more closely to the more modern sources (Figure 6, cluster $C$ which is dominated by sources from the 1900s) than to the earlier sources (Figure 6, cluster B which is dominated by sources from the 1900s). The fact that this last source (Cooper 1840) clusters with the European sources reveals that in spite of its title's implied reference to an "Indian Physician" it is European knowledge, not Native American knowledge. Religious sect affiliation (Amish vs. Mennonite) are completely irrelevant to the data clustering in all cases.

Since all of the historical culinary sources used were Anabaptist in origin, nothing can be said about interactions between the Mennonites and surrounding food-cultures.
However, with the inclusion of the English and indigenous Delaware sources in the medical data, more can be said on this topic. The three sources linked to the Delaware are distinct from all of the sources from European cultures save one, the self-published booklet, Wieand (1970). All plants listed in the booklet include Latin names, as well as their uses, and there are many line drawings of selected plants. These data raise a tantalizing question-is this data source an aberration? Or, did there once exist an oral knowledge tradition that differed from both the written knowledge tradition and the oral knowledge collected in this study? Unfortunately, Mr. Wieand is no longer living and did not record his data collection method, though in a telephone conversation between the lead author and his daughter it was learned that he had collected information from local individuals and collected samples of the plants discussed by preserving them in canning jars for the purpose of showing others. However, since his method is unknown there is not enough information present to distinguish between the questions this information raises.

Another source, Hohman (2007), is noteworthy since it represents the powwow healing tradition. While this book is primarily a book of faith healing methods, it contains a large number of references to plants, and these fit neatly into Figure 6, data cluster B of European knowledge.

\section{Geography}

Geography may be evaluated from the interview results. The difference between the northern data points (Appendix 1, interviews 17-20) and the remainder of the data is greater than any other differences observed. The apparent determinants of this difference are dependence on commerce (Appendix 1, row 6) and the importance of the Pennsylvania German dialect (Appendix 1, rows $7-10)$. This group has diverged from the other groups interviewed. The difficulty with the presently available data is that there are two possible explanatory actors: the geographic separation from better farming land and increased dependence on commerce. While participating in a casual conversation with one of the northern participants, this finding was mentioned. The participant (who had moved to northern Pennsylvania from southeastern Pennsylvania) quickly replied, "Well of course, the growing season is shorter here than where we used to live." This is confirmed by climatic differences; most of Bradford County, Pennsylvania (where the northern interviews were conducted), is classified by the United States Department of Agriculture (USDA Plant Hardiness Zone Map 2012) as "zone $5 b$ " (minimum winter temperature of $-26.1^{\circ} \mathrm{C}$ ) whereas southeastern Pennsylvania is a mixture of "zone $6 \mathrm{~b}$ " with a minimum temperature of $-20.6^{\circ} \mathrm{C}$ and "zone $7 \mathrm{a}$ " with a minimum temperature of $-17.8^{\circ} \mathrm{C}$. This would argue for geography being a differentiating and possibly causal explanation for variation. 


\section{Brown et al. - Traditional Botanical Knowledge of the Plain Mennonites: Time, change, and knowledge transitions}

\section{Degree of religious conservatism}

As discussed above, the northern interviews formed the most distinct set within the data, and climate has been mentioned as a potential explanation for this. However as all northern participants were Mid Atlantic Fellowship Mennonites, and none of the participants from other regions belong to this group, this difference may also be explained by cultural attributes unrelated to geography. This point is underscored by the fact that the Pennsylvania German dialect is unimportant in this group, and while the Mennonite population is smaller in the northern regions than further south (personal observations) there is no geographic necessity for this cultural change. Because the four northern interviews represent a population with distinct geographic and cultural factors (being the least culturally conservative of those interviewed), it is not possible to truly distinguish which or what combination of these is responsible for creating the differences in botanical knowledge observed. Further research, including larger data sets, is needed to better understand these observations.

\section{Consideration of the hypotheses of Leonti et al. (2009, 2010) and Leonti (2011)}

The data pertaining to historical medical sources support the findings and assertions of Leonti et al. (2009, 2010) and Leonti (2011). The first of these observations is the high degree of conservatism in this literate culture. The knowledge reprinted in Weaver (2001) is that of a firstgeneration Mennonite immigrant during the time of the American Revolutionary War, and it clusters closely with the most modern Amish and Mennonite texts. The second is the observation that written sources can lead to knowledge change and homogenization. This is supported by an interview participant (introduced by another community member as one of the most interested and knowledgeable individuals around) who named seven medicinal plants and five herbals to which the family referred when needed. Only one of the herbals was of Anabaptist origin. A second participant introduced in a similar manner referred to an essential oils catalog during the interview. Another observation of reliance on the written word was that when asked what plants were cultivated in the garden, it was common for a participant to retrieve a garden diagram to use as a memory aid in the interview. Herr et al. (2007) contains notes on the author's gardens, orchards, and local plants showing that this is not a strictly modern phenomenon.

\section{Conclusions}

The observations described here present a core idea adding to the theoretical framework describing the interactions between people and plants: contact between cultures can result in greater/more complex plant knowledge. For example, from this study modern culinary knowledge includes more diversity than in the past. This likely is related to trade, as well as increasing outside contact. For example, in interview 19 the informant had previously undertaken missionary work in Haiti, and the plant list included core Mennonite knowledge from northern Pennsylvania as well as tropical plant knowledge of lemongrass and breadfruit. This is an example of a widely observed phenomenon of cultural knowledge enrichment (rather than loss) through processes of contact and commerce. This is the opposite of the frequent focus of ethnobotanical research - "culture loss" and "cultural degradation."

The study tested hypotheses that time, geography, and degree of religious conservatism impact the retention of botanical knowledge. Of these, time was by far the most important, though there are elements of the interview data pertaining to culinary knowledge that prevent geography and sect differences from being completely discounted as influential factors. In all, the cultural conservatism in relation to plant usage is remarkable and is likely to be related to the long term literacy of this culture. There is, however, a question raised by one observation in the data that can't be answered presently: Wieand (1970) is more closely related to the Delaware Native American data than the European data. More data, in the form of a larger study, will be necessary to make sense of this information and therefore to tell the full story of botanical knowledge change over the last century in the Pennsylvania German community.

\section{Acknowledgments}

The authors would like to extend their gratitude to University of Hawai $i$ at Mānoa for graduate assistantship funding, as well as all of the kind participants in the interview portion of this study for taking time out of their busy schedules. The staff of the Muddy Creek Farm Library and the Lancaster Mennonite Historical Society were particularly helpful in locating and making available several of the historical texts used here. Thank you.

\section{Literature Cited}

Bernard, R.H. 2002. Research Methods in Anthropology: Qualitative and quantitative approaches. Third edition. AltaMira Press, Oxford, England.

Brendle, E.M. 1973. Weaverland Mennonite Cookbook. Publisher and location of publication unknown. [Copy used in the collection of the Lancaster Mennonite Historical Society.]

Buenz, E.J., D.J. Schnepple, B.A. Bauer, P.L. Elkin, J.M. Riddle \& T.J. Motley. 2004. Techniques: Bioprospecting historical herbal texts by hunting for new leads in old tomes. Trends in Pharmacological Sciences 25(9):494498. dx.doi.org/10.1016/j.tips.2004.07.003 
Colester, J.S. 1992. Old Amish Recipes. Bear Wallow Books, Nashville, Indiana, U.S.A.

Cooper, J.W. 1840. The Experienced Botanist or Indian Physician. John Bear, Lancaster, Pennsylvania, U.S.A.

Correll, E.H., M.L. Huffines \& D.J. Rempel Smucker. 1991. The Mennonite agricultural model in the German Palatinate. Pennsylvania Mennonite Heritage 14(4):2-13.

Frederick, J.G. 1946. The Pennsylvania Dutch and Their Cookery. The Business Bourse, Publisher, New York, New York.

Hammer, Ø., D.A.T. Harper \& P.D. Ryan. 2001. PAST: Paleontological statistics software package for education and data analysis. Palaeontologia Electronica 4(1):1-9.

Heinrich, M., J. Kufer, M. Leonti \& M. Pardo-de-Santayana. 2006. Ethnobotany and ethnopharmacology - Interdisciplinary links with the historical sciences. Journal of Ethnopharmacology 107(2):157-160. dx.doi.org/10.1016/j. iep.2006.05.035

Herr, B.G. 2007. Recollections of life in Strasburg Township, Lancaster County, Pennsylvania, 1808-1829: Part five. Annotation by C.C. Wenger. Transcription by L.M. Lehman. Pennsylvania Mennonite Heritage 30(2):2-18.

Hohman, J.G. 2007. Pow-wows or, Long Lost Friend. NuVision Publications, LLC, Sioux Falls, South Dakota, U.S.A.

Kauffman, A.L. 1986. Recipes, Remedies and Salves. Whitmore Printing, New Holland, Pennsylvania, U.S.A.

Kendig, F.D., J.W. Kendig \& C.C. Wenger. 2004. Special remedies for home and farm. Pennsylvania Mennonite Heritage 27(2):2-13.

Kufer, J., M. Heinrich, H. Förther \& E. Pöll. 2005. Historical and modern medicinal plant uses - The example of the Ch'orti' Maya and Ladinos in eastern Guatemala. Journal of Pharmacy and Pharmacology 57(9):1127-1152. dx.doi. org/10.1211/jpp.57.9.0008

Kreibel, D.W. 2008. Powwowing among the Pennsylvania Dutch. Pennsylvania State University Press, University Park, Pennsylvania, U.S.A.

Larson, R., R.P. Hostetler \& B.H. Edwards. 2001. Algebra and Trigonometry: A graphing approach. Third Edition. Houghton Mifflin Company, Boston, Massachusetts, U.S.A.

Leonti, M., L. Casu, F. Sanna \& L. Bonsignore. 2009. A comparison of medicinal plant use in Sardinia and Sicily-De Materia Medica revisited? Journal of Ethno- pharmacology 121(2):255-267. dx.doi.org/10.1016/j. iep.2008.10.027

Leonti, M., S. Cabras, C.S. Weckerle, M.N. Solinas \& L. Casu. 2010. The causal dependence of present plant knowledge on herbals-Contemporary medicinal plant use in Campania (Italy) compared to Matthioli (1568). Journal of Ethnopharmacology 130(2):379-391. dx.doi. org/10.1016/j.jep.2010.05.021

Leonti, M. 2011. The future is written: Impact of scripts on the cognition, selection, knowledge and transmission of medicinal plant use and its implications for ethnobotany and ethnopharmacology. Journal of Ethnopharmacology 134(3):542-555. dx.doi.org/10.1016/j.jep.2011.01.017

Levine, N. \& A. Stuckey. 2001. A selection of remedies from the John Reist notebook. Pennsylvania Mennonite Heritage 24(1):2-22.

Lustig, L.S. 1967. Editor of Pennsylvania Dutch Cookbook of Fine Old Recipes. Culinary Arts Press, Reading, Pennsylvania, U.S.A.

McGrath, W.R. 1985. Amish Folk Remedies: For plain and fancy ailments. Freeport Press, Inc., Freeport, Ohio, U.S.A.

Miller, A. 1985. More Country Cooking: Favorite recipes from the Amish and their friends from across the nation. Edgewood Press, [city], U.S.A.

Miller, D. 2005. Home Remedies from Amish Country. Abana Books, Ltd. Millersburg, Ohio, U.S.A.

Moerman, D.E. 1998. Native American Ethnobotany. Timber Press, Portland, Oregon, U.S.A.

Nguyen, M.T. 2007. Community dynamics and functional stability: A recipe for cultural adaptation and continuity. Economic Botany 61:337-346. dx.doi.org/10.1663/00130001(2007)61[337:CDAFSA]2.0.CO:2

Quillin, P. 1996. Amish Folk Medicine: Home remedies using foods, herbs and vitamins. The Leader Company, Inc., North Canton, Ohio, U.S.A.

Ramirez, C.R. 2007. Ethnobotany and the loss of traditional knowledge in the $21^{\text {st }}$ century. Ethnobotany Research and Applications 5:245-247.

Rhoads, A.F. \& T.A. Block. 2007. The Plants of Pennsylvania: An illustrated manual. Second edition. University of Pennsylvania Press, Philadelphia, Pennsylvania, U.S.A.

Smith, C.H. 1941. The Story Of The Mennonites. The Mennonite Book Concern, Berne, Indiana, U.S.A. 


\section{Brown et al. - Traditional Botanical Knowledge of the Plain Mennonites: Time, change, and knowledge transitions}

Thomson, E.C. \& J. Zhang. 2006. Comparative cultural salience: Measures using free-list data. Field Methods 18(4):398-412. dx.doi.org/10.1177/1525822X06293128

USDA. 2012. Plant Hardiness Zone Map. Agricultural Research Service, United States Department of Agriculture. http://planthardiness.ars.usda.gov

Van Diver, B.B. 1990. Roadside Geology of Pennsylvania. Mountain Press Publishing Company, Missoula, Montana, U.S.A.

Vollmer, W.M. 1867. The United Stated Cookbook: A complete guide for ladies, housekeepers and cooks. Translated by J.C. Oehlschlager Schaefer. Koradi, Philadelphia, Pennsylvania, U.S.A.

Walton, R.B. 2005. Conestoga Heritage Cooking Circa 1880s-1950s. Personally printed, Conestoga, Pennsylvania, U.S.A.
Weaver, W.W. 1982. The Swiss Anabaptist emigration to Germany. Pennsylvania Mennonite Heritage 5(1):2-8.

Weaver, W.W. 1983. Sauerkraut Yankees: Pennsylvania German foods and foodways. University of Pennsylvania Press, Philadelphia, Pennsylvania, U.S.A.

Weaver, W.W. 2001. Sauer's Herbal Cures. Routledge, New York, New York, U.S.A.

Wieand, P.R. 1970. Folk Medicinal Plants used in the Pennsylvania Dutch Country. Third printing. Wieand's Pennsylvania Dutch, Allentown, Pennsylvania, U.S.A.

Weller, S.C. \& A.K. Romney. 1988. Systematic Data Collection. Sage Publications, Inc., Newbury Park, London, United Kingdom.

Women's Missionary Society. c1930s. Cook Book of Practical Recipes Contributed by Family and Friends of Zion Mennonite Church Souderton, PA. W.F. Goettler and Son, Printers, Souderton, Pennsylvania, U.S.A. 


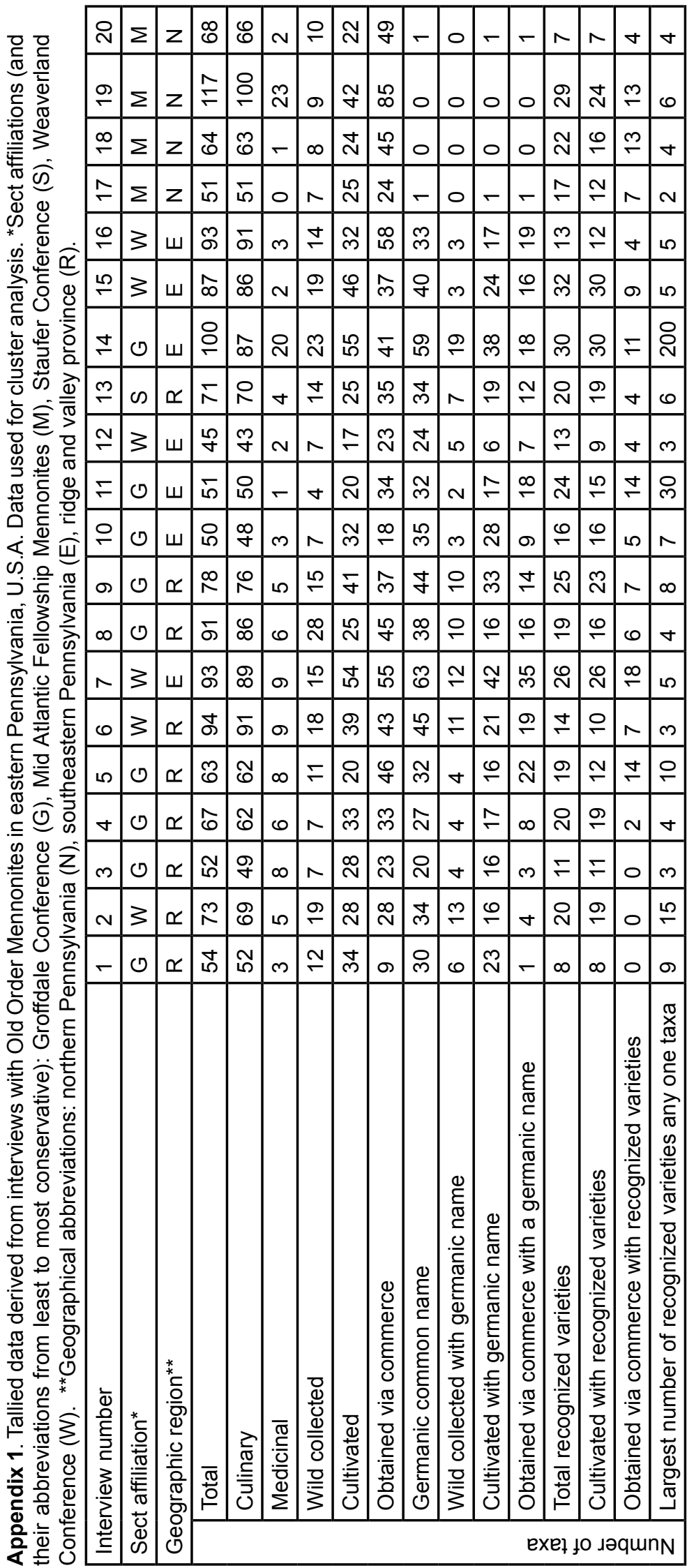



Time, change, and knowledge transitions

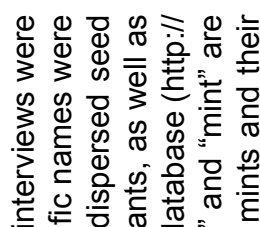

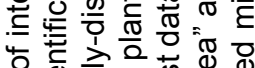

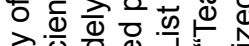

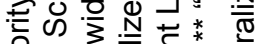

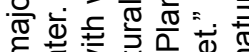

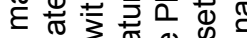

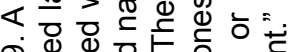

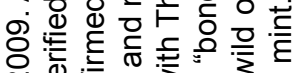

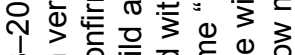

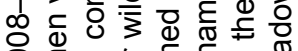
N

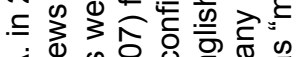
他.

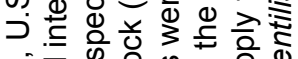

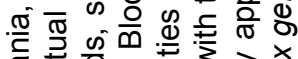
> 更 势

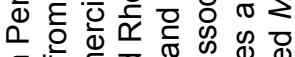
年

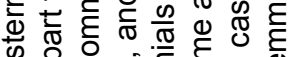
ष

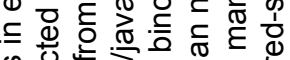
过 항 O

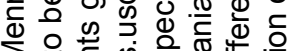
र क

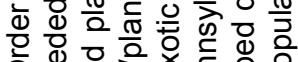
过娄

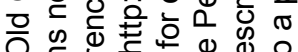

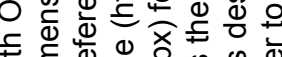
了. 象 0 क्ष

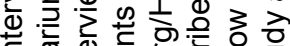

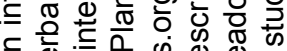

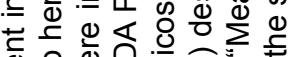
过 은

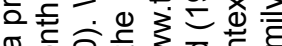

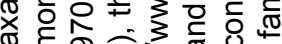

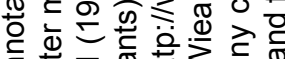

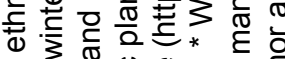
Z 空

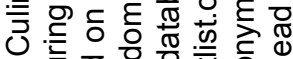
N

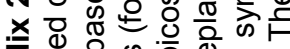

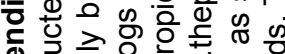

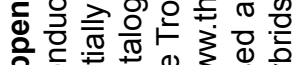

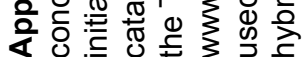

\begin{tabular}{|c|c|c|c|c|c|c|c|c|c|c|c|c|c|c|c|c|c|c|c|c|}
\hline ని & $\tau$ & 0 & 0 & 0 & - & - & 0 & - & 0 & - & - & - & - & - & 0 & 0 & 0 & 0 & - & 0 \\
\hline$\stackrel{9}{\square}$ & - & - & 0 & 0 & - & - & 0 & - & - & - & 0 & - & - & - & 0 & - & 0 & - & - & 0 \\
\hline$\stackrel{\infty}{\sim}$ & 0 & 10 & 0 & 0 & - & - & 0 & 0 & 0 & - & 0 & - & 0 & - & 0 & 10 & 0 & 0 & - & 0 \\
\hline$₹$ & - & 0 & 0 & 0 & 0 & 0 & 0 & 0 & 0 & - & - & - & 0 & - & 0 & 0 & 0 & - & - & 0 \\
\hline$\stackrel{\circ}{0}$ & $\tau$ & - & 0 & 0 & - & - & 0 & - & 0 & 0 & - & - & - & - & 0 & 0 & 0 & - & 0 & 0 \\
\hline$\stackrel{20}{2}$ & 0 & - & 0 & 0 & - & 0 & - & 0 & 0 & 0 & - & 0 & - & 0 & - & 0 & 0 & 0 & - & 0 \\
\hline \pm & 0 & 0 & 0 & 0 & $r$ & - & - & 0 & - & - & - & 0 & - & 0 & 0 & 0 & 0 & - & - & 0 \\
\hline$\stackrel{m}{=}$ & 0 & 0 & 0 & 0 & - & - & - & 0 & 0 & 0 & - & - & - & - & 0 & 0 & 0 & 0 & - & 0 \\
\hline$\stackrel{\text { T }}{ }$ & 0 & 0 & 0 & - & - & - & 0 & 0 & 0 & 0 & 0 & - & - & 0 & 0 & 0 & 0 & 0 & - & 0 \\
\hline$\mp$ & 0 & 0 & 0 & 0 & - & 0 & 0 & 0 & 0 & - & - & 0 & - & - & 0 & 0 & 0 & - & - & 0 \\
\hline 우 & 0 & 0 & 0 & - & - & 0 & 0 & 0 & 0 & 0 & - & - & - & - & 0 & 0 & 0 & - & 0 & 0 \\
\hline 0 & - & 0 & 0 & - & - & - & 0 & 0 & 0 & - & - & 0 & - & - & 0 & 0 & 0 & - & - & 0 \\
\hline$\infty$ & - & 0 & - & 0 & - & - & 0 & 0 & 0 & 0 & - & - & - & - & 0 & 0 & 0 & - & - & $r$ \\
\hline$\Lambda$ & - & 0 & 0 & - & - & 0 & - & - & 0 & - & - & - & - & - & - & 0 & - & - & - & 0 \\
\hline 0 & - & 0 & 0 & 0 & - & - & 0 & - & 0 & 0 & - & 0 & - & - & 0 & 0 & 0 & 0 & - & 0 \\
\hline in & 0 & 0 & 0 & 0 & - & - & 0 & 0 & 0 & 0 & - & 0 & - & - & 0 & 0 & 0 & - & - & 0 \\
\hline$\forall$ & 0 & 0 & 0 & 0 & - & 0 & 0 & 0 & 0 & 0 & 0 & - & - & 0 & 0 & 0 & 0 & - & - & 0 \\
\hline m & 0 & 0 & 0 & - & - & - & 0 & 0 & 0 & 0 & 0 & - & 0 & 0 & 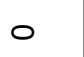 & 0 & 0 & 0 & - & 0 \\
\hline$N$ & - & 0 & 0 & 0 & - & - & 0 & 0 & 0 & 0 & 0 & 0 & 0 & 0 & 0 & 0 & 0 & - & - & 0 \\
\hline- & - & 0 & 0 & 0 & 0 & 0 & 0 & 0 & 0 & - & 0 & 0 & 0 & - & 0 & 0 & 0 & - & - & 0 \\
\hline$\left|\begin{array}{c}\frac{1}{\pi} \\
\frac{\pi}{3} \\
0 \\
\frac{\pi}{2} \\
\frac{5}{0} \\
\bar{\nu}\end{array}\right|$ & 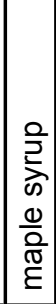 & $\sum_{\bar{x}}^{\bar{z}}$ & 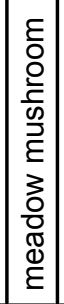 & 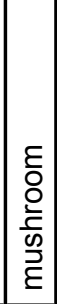 & . & 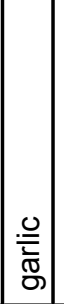 & \begin{tabular}{|c|}
$\frac{0}{3}$ \\
$\frac{0}{3}$ \\
$\frac{0}{\bar{T}}$ \\
$\overline{\bar{T}}$ \\
\end{tabular} & $\stackrel{D}{J}_{0}^{\mathscr{D}}$ & 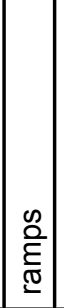 & $\mid$\begin{tabular}{c|}
3 \\
0 \\
$\frac{1}{19}$ \\
$\mathbb{0}$ \\
\end{tabular} & $\begin{array}{l}\frac{0}{0} \\
\frac{0}{0} \\
\frac{\mathbb{d}}{2} \\
. \frac{\bar{c}}{2}\end{array}$ & $\overline{\bar{z}}$ & $\left|\begin{array}{l}\vec{\theta} \\
\frac{\hat{d}}{0} \\
\mathcal{0}\end{array}\right|$ & 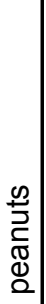 & 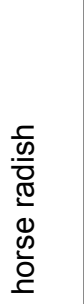 & 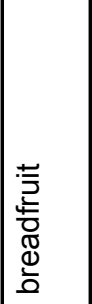 & 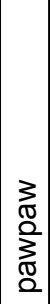 & 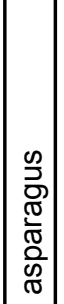 & $\frac{\infty}{\pi}$ & 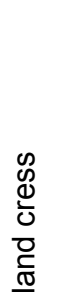 \\
\hline 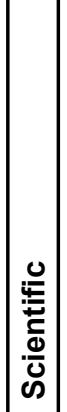 & 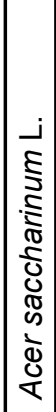 & 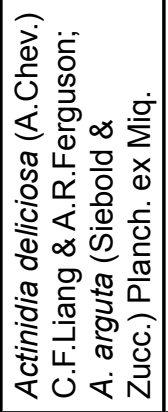 & 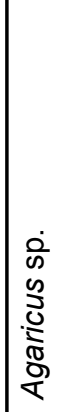 & & 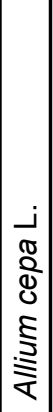 & 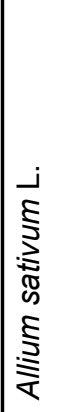 & & 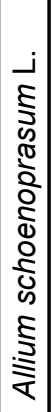 & 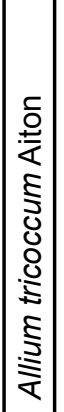 & 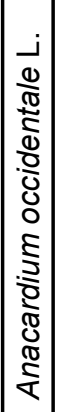 & 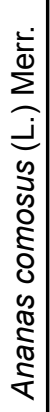 & 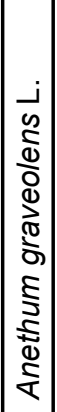 & 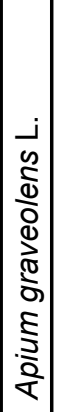 & 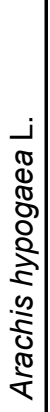 & 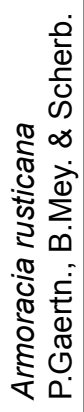 & 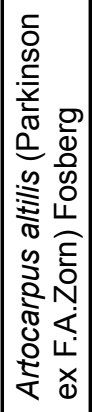 & 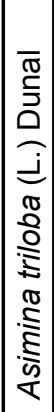 & 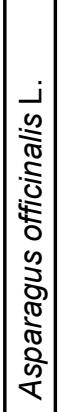 & 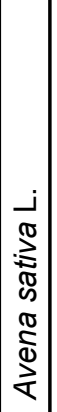 & 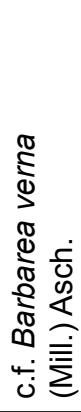 \\
\hline
\end{tabular}

www.ethnobotanyjournal.org/vol12/i1547-3465-12-571.pdf 


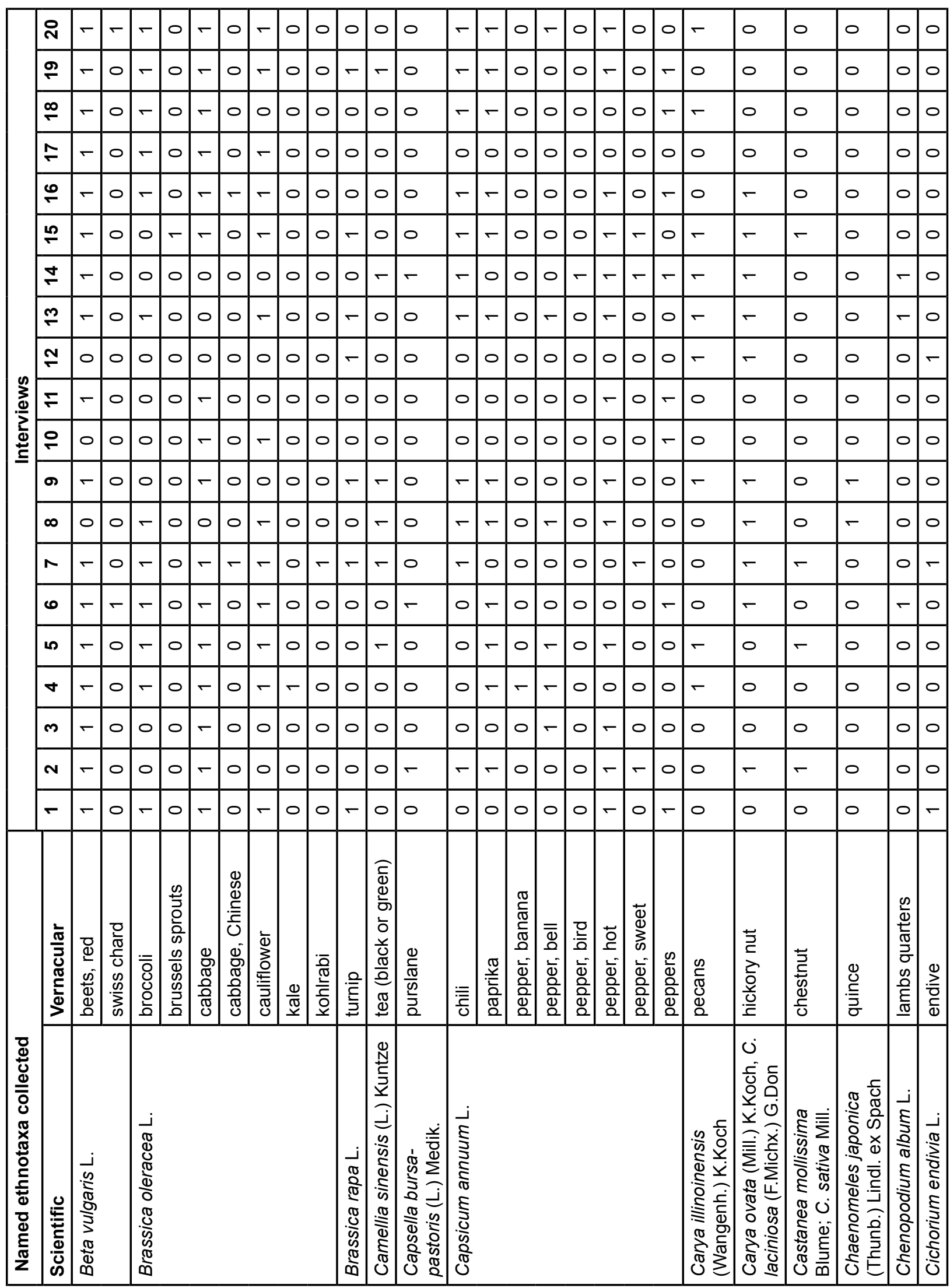


Brown et al. - Traditional Botanical Knowledge of the Plain Mennonites:

Time, change, and knowledge transitions

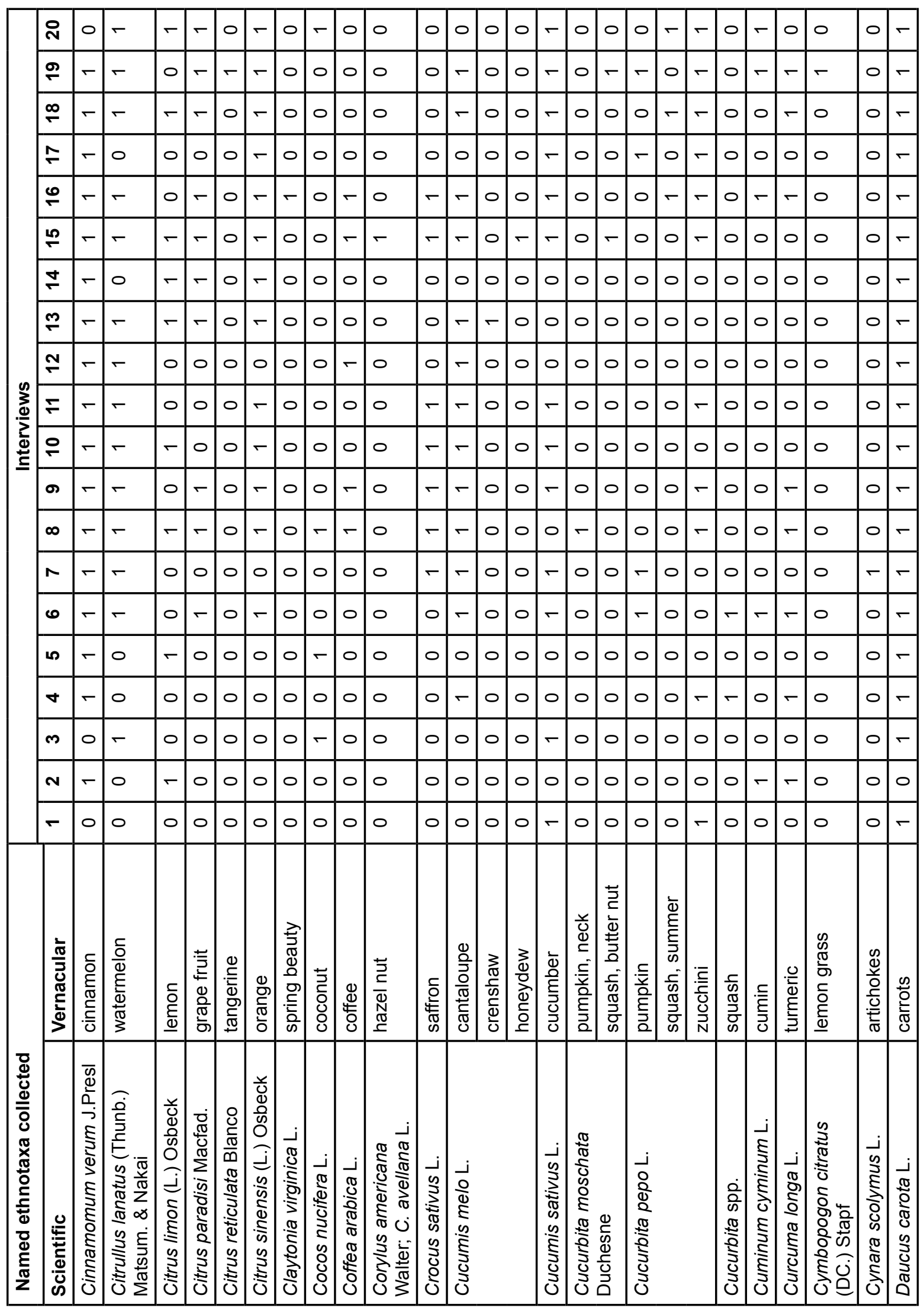




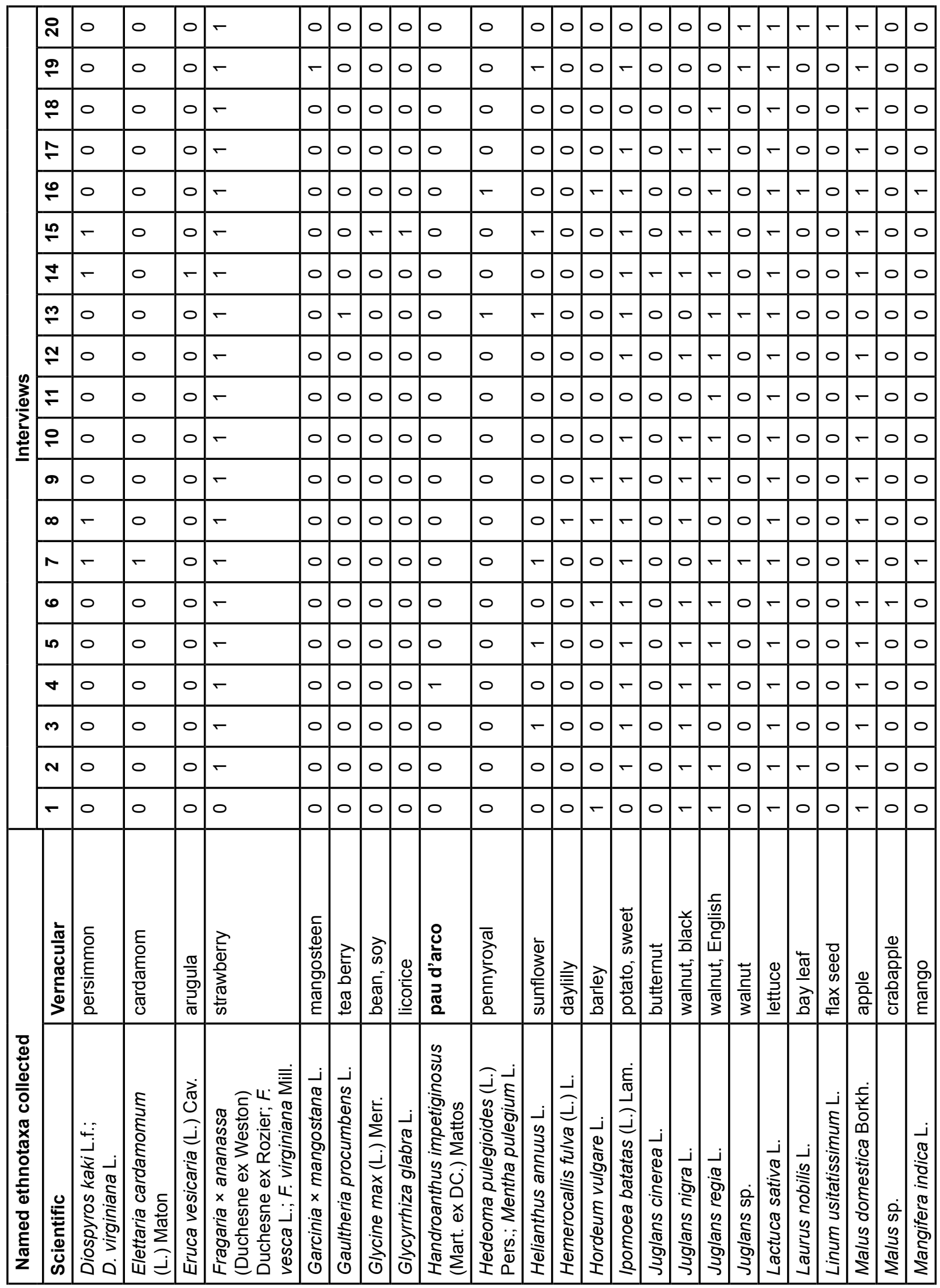


Brown et al. - Traditional Botanical Knowledge of the Plain Mennonites: Time, change, and knowledge transitions

\begin{tabular}{|c|c|c|c|c|c|c|c|c|c|c|c|c|c|c|c|c|c|c|c|c|c|c|c|c|c|c|c|}
\hline & ని & 0 & 0 & $\leftarrow$ & 0 & 10 & 0 & 0 & 0 & 0 & 0 & 0 & 0 & 0 & $\mid-$ & 0 & - & 0 & $\mid-$ & 0 & - & 0 & 0 & 0 & 0 & 0 & 0 \\
\hline & 9 & 0 & 0 & . & - & 0 & 0 & 0 & 0 & 0 & ol & - & 0 & 0 & - & $r$ & 0 & 0 & $r$ & - & - & 0 & 0 & 0 & - & 0 & 0 \\
\hline & $\stackrel{\infty}{\Gamma}$ & & 0 & $r$ & - & 0 & 0 & 0 & \begin{tabular}{|l|}
0 \\
\end{tabular} & $r$ & o & 0 & 0 & 0 & 0 & - & - & - & $r$ & 0 & - & 0 & \begin{tabular}{|l|}
0 \\
\end{tabular} & 0 & 0 & 0 & 0 \\
\hline & $\approx$ & $c$ & 0 & 0 & 0 & 0 & 0 & 0 & 0 & $r$ & 0 & 0 & 0 & 0 & - & 0 & 10 & 0 & 10 & 0 & 0 & 0 & 0 & 0 & 0 & 0 & 0 \\
\hline & $\ddot{0}$ & $c$ & 0 & $r$ & 0 & 0 & 0 & - & - & o & - & 0 & 0 & 0 & r & - & - & 0 & - & 0 & - & - & 0 & 0 & 0 & 0 & - \\
\hline & $\stackrel{20}{2}$ & 0 & 0 & 0 & 0 & 0 & 0 & 0 & - & $c$ & ol & - & - & 0 & $\mid-$ & - & - & - & 0 & 0 & - & 0 & 0 & 0 & 0 & 0 & 0 \\
\hline & 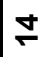 & 0 & $1-$ & 1 & 10 & - & - & 0 & 0 & $c$ & 0 & 0 & 0 & 0 & . & 0 & 0 & 0 & - & 0 & - & 0 & 0 & - & 0 & 0 & 0 \\
\hline & $m$ & 0 & 0 & - & 0 & 0 & 0 & 0 & - & 0 & م & 0 & 0 & 0 & - & - & - & 0 & - & 0 & - & - & 0 & 0 & 0 & 0 & 0 \\
\hline & & 0 & 0 & 17 & 0 & 0 & 0 & 0 & -1 & 0 & 0 & 0 & 0 & 0 & 0 & 0 & 0 & 0 & 0 & 0 & - & 0 & 0 & 0 & 0 & 0 & 0 \\
\hline 3 & $F$ & 10 & 0 & 10 & 0 & 0 & 0 & 0 & 0 & - & 0 & 0 & 0 & - & - & 0 & 0 & 0 & 0 & 0 & 0 & 0 & 0 & 0 & 0 & 0 & 0 \\
\hline & 웅 & 0 & 0 & - & 0 & 0 & 0 & 0 & - & $r$ & 0 & 0 & 0 & - & 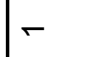 & 0 & 0 & 0 & 0 & 0 & 0 & 0 & 0 & 0 & 0 & 0 & 0 \\
\hline & o & 10 & 0 & 10 & 0 & 0 & 0 & 0 & 0 & r & 0 & 0 & 0 & 0 & - & 0 & - & - & - & 0 & - & 0 & 0 & 0 & 0 & 0 & 0 \\
\hline & $\infty$ & 10 & 0 & - & 0 & 0 & 0 & 0 & - & $c$ & 0 & 0 & - & - & - & - & - & 0 & - & 0 & - & 0 & 0 & 0 & 0 & 0 & 0 \\
\hline & $\sim$ & - & 0 & - & 0 & 0 & 0 & 0 & - & 0 & 0 & 0 & - & - & 0 & - & - & - & 0 & 0 & 0 & - & 0 & 0 & 0 & - & 0 \\
\hline & 0 & 0 & 0 & - & - & 0 & 0 & 0 & - & 0 & 0 & 0 & - & - & - & - & 0 & - & - & - & - & - & - & 0 & 0 & 0 & 0 \\
\hline & in & 0 & 0 & - & 0 & 0 & 0 & 0 & - & - & 0 & 0 & 0 & 0 & - & - & 0 & - & - & 0 & - & 0 & 0 & 0 & 0 & 0 & 0 \\
\hline & $\nabla$ & 0 & 0 & - & 0 & 0 & 0 & 0 & - & 0 & 0 & 0 & 0 & 0 & 0 & - & 0 & 0 & - & 0 & - & 0 & - & 0 & 0 & 0 & 0 \\
\hline & $m$ & 10 & 0 & c & 0 & 0 & 0 & 0 & - & 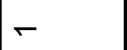 & 0 & - & 0 & - & 0 & - & 0 & - & 0 & 0 & 0 & 0 & 0 & 0 & 0 & 0 & 0 \\
\hline & N & 10 & 0 & in & 0 & 0 & 0 & 10 & - & 10 & 0 & 0 & - & - & $\int_{0}$ & - & 10 & - & - & 10 & - & 0 & 0 & 0 & 0 & 0 & 0 \\
\hline & - & 0 & 0 & - & - & 0 & 0 & 0 & - & 0 & 0 & 0 & 0 & - & 0 & - & 0 & - & 0 & 0 & 0 & 0 & 0 & 0 & 0 & 0 & 0 \\
\hline & 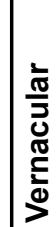 & 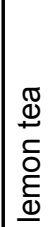 & 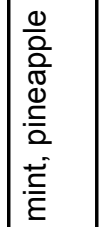 & 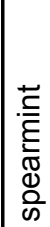 & . & 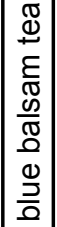 & 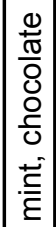 & 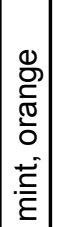 & 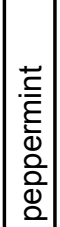 & 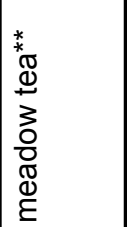 & 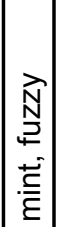 & 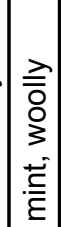 & $\begin{array}{l}\bar{\Phi} \\
\bar{\partial} \\
\bar{\varepsilon}\end{array}$ & $\mid \begin{array}{l}\frac{3}{2} \\
\bar{D} \\
\frac{0}{\bar{D}} \\
\varepsilon\end{array}$ & 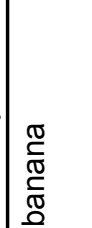 & 兽 & 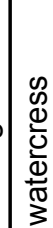 & 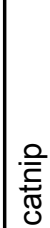 & $\overline{\overline{\mathscr{Q}}}$ & 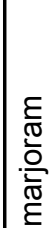 & 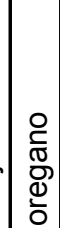 & $\stackrel{Ð}{.}$ & 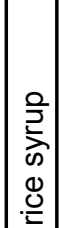 & 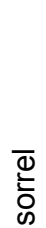 & $\begin{array}{l}0 \\
\Phi \\
\Phi \\
\infty \\
0 \\
0 \\
0 \\
0\end{array}$ & 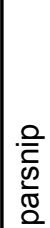 & 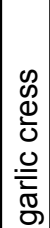 \\
\hline 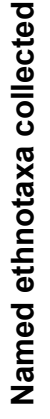 & 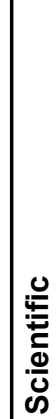 & 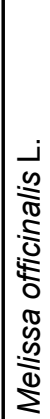 & 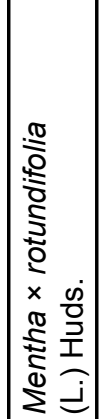 & 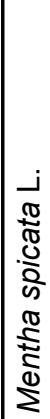 & 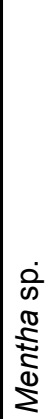 & 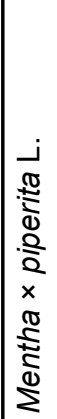 & & & & 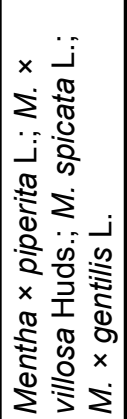 & 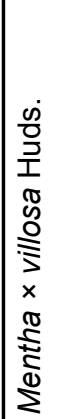 & & $\begin{array}{l}\frac{0}{0} \\
\frac{\pi}{2} \\
\frac{d}{d} \\
\frac{1}{0} \\
\frac{0}{2}\end{array}$ & 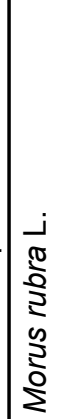 & 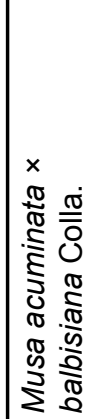 & 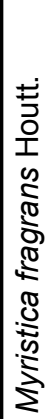 & 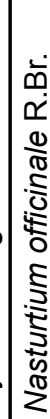 & 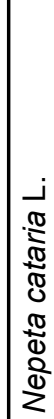 & 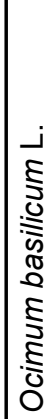 & 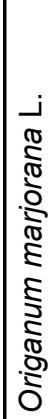 & 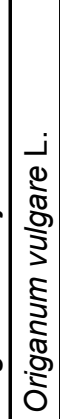 & 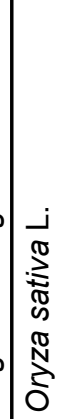 & & 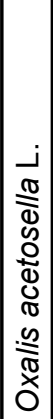 & 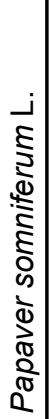 & 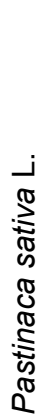 & 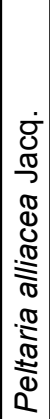 \\
\hline
\end{tabular}




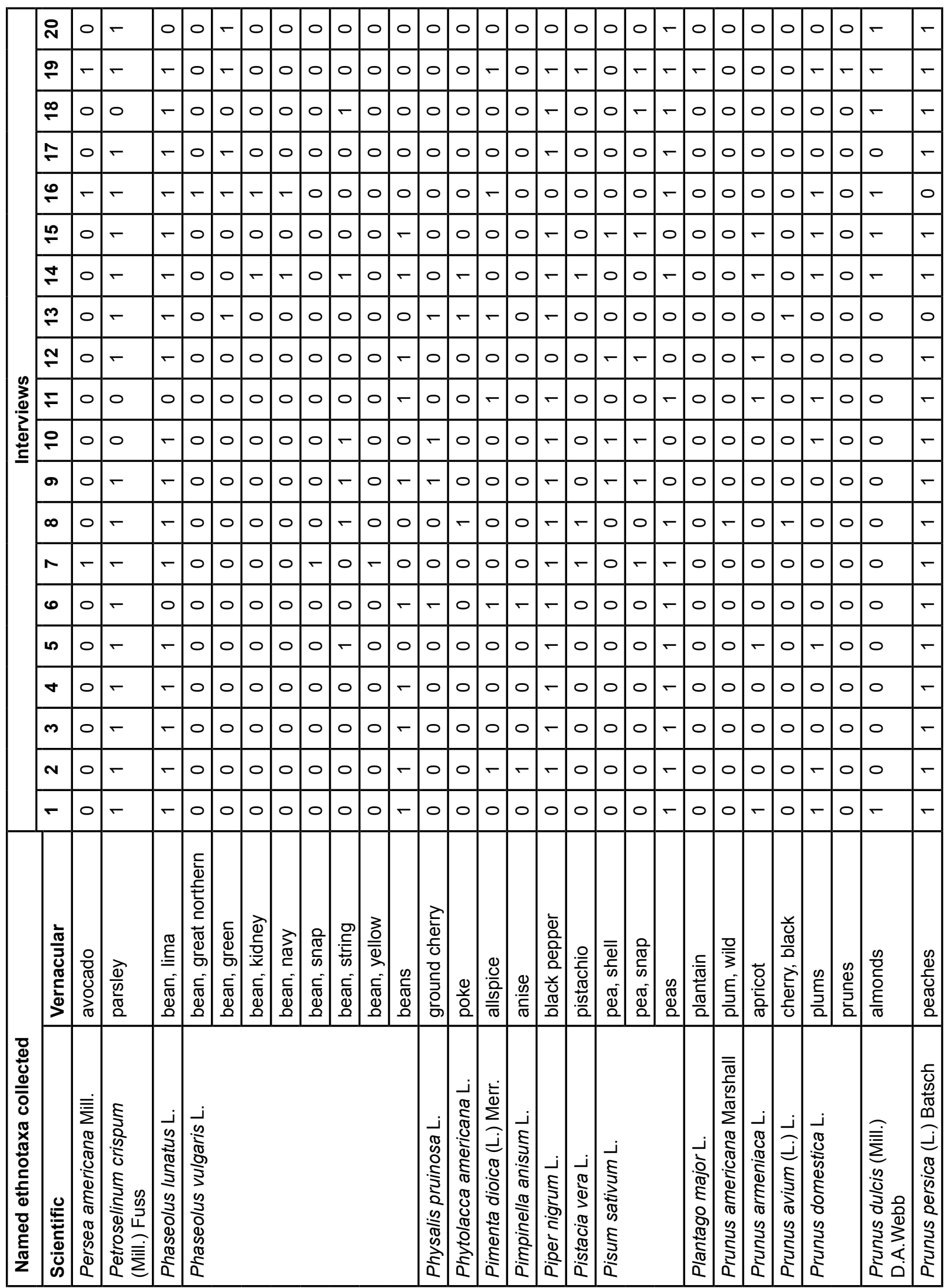


Brown et al. - Traditional Botanical Knowledge of the Plain Mennonites: Time, change, and knowledge transitions

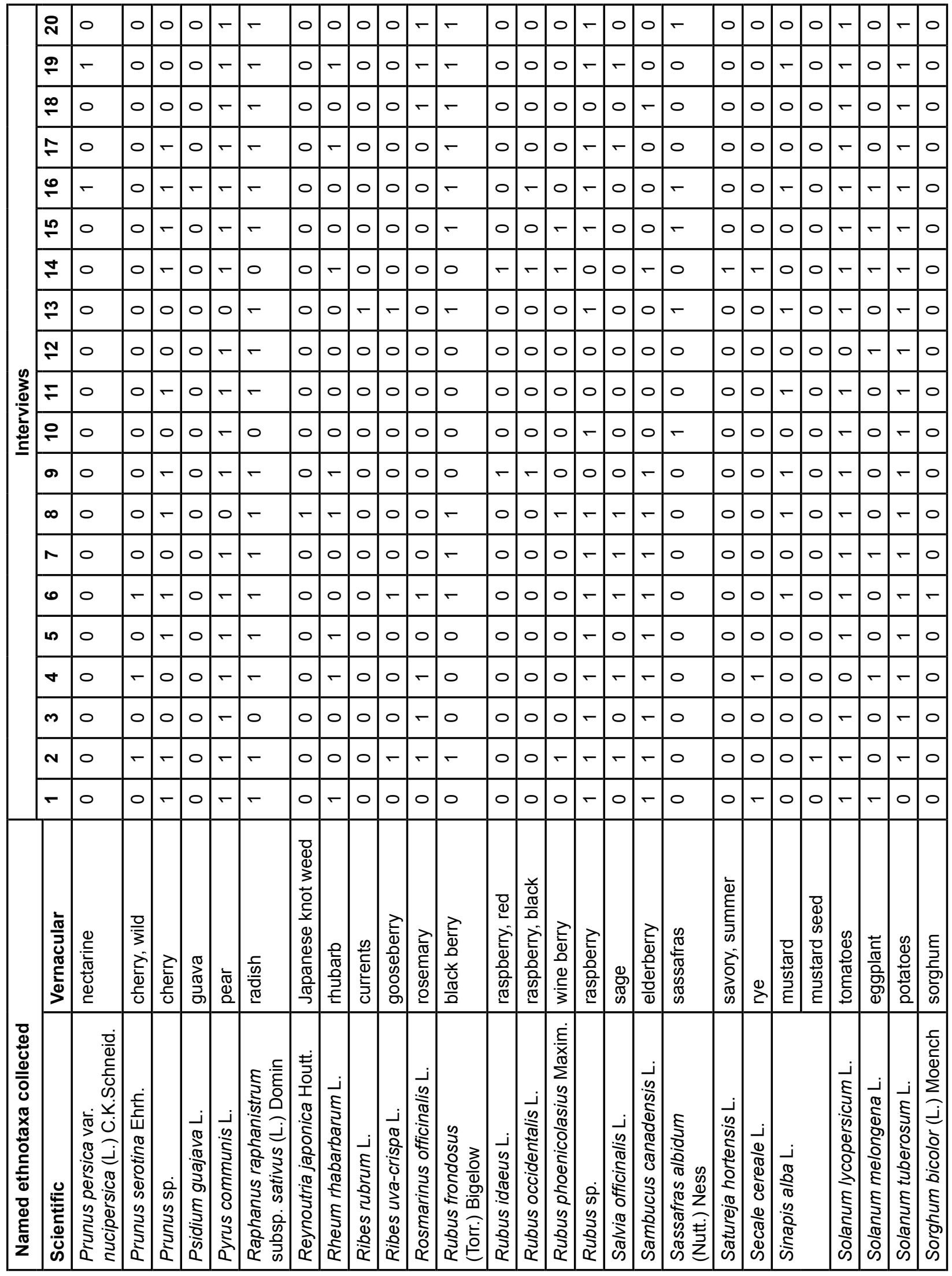




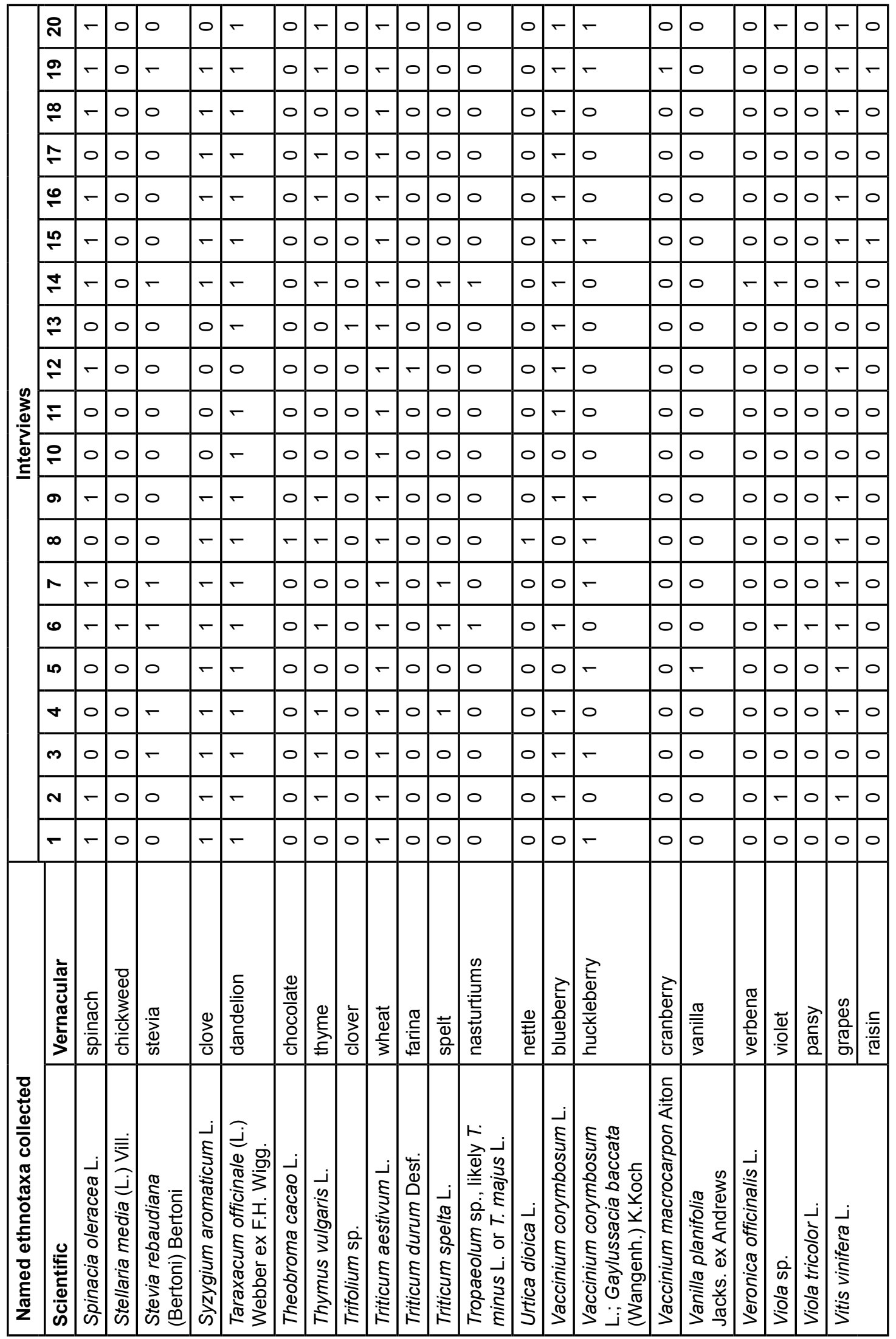


Brown et al. - Traditional Botanical Knowledge of the Plain Mennonites:

Time, change, and knowledge transitions

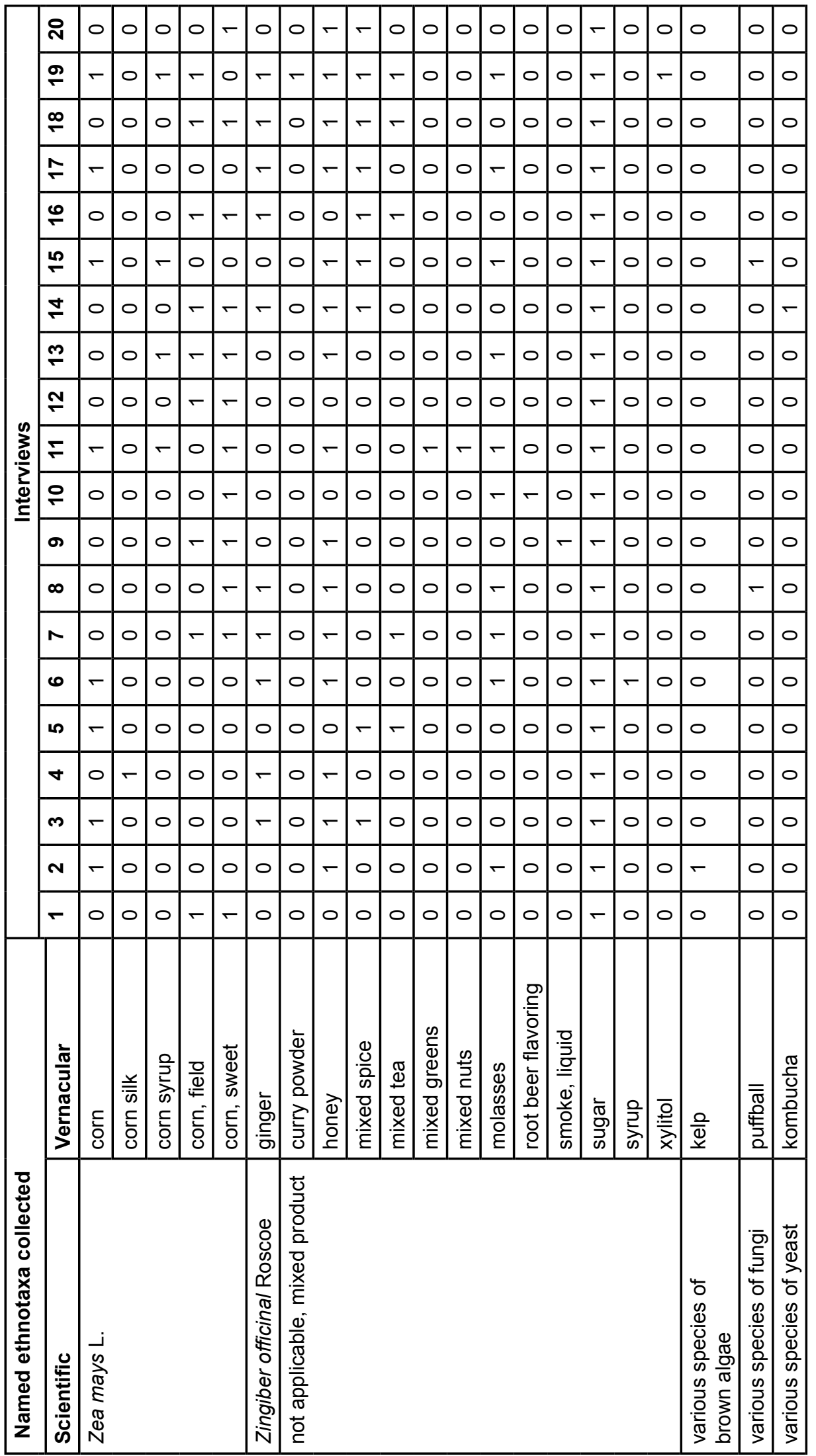




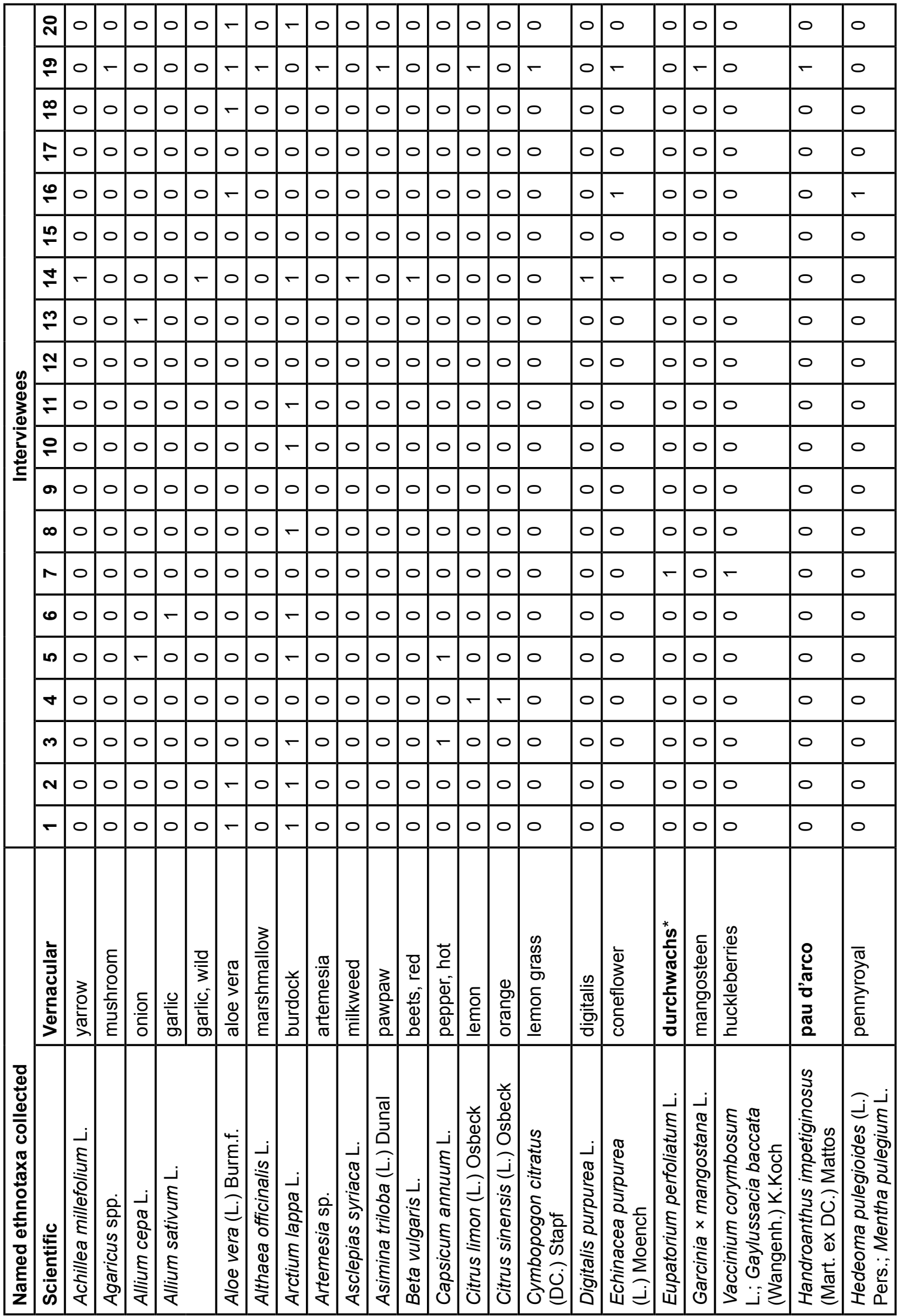


Brown et al. - Traditional Botanical Knowledge of the Plain Mennonites:

Time, change, and knowledge transitions

\begin{tabular}{|c|c|c|c|c|c|c|c|c|c|c|c|c|c|c|c|c|c|c|c|c|c|c|c|c|c|c|c|c|}
\hline సి & 10 & 0 & 0 & 0 & 0 & 0 & 0 & 0 & 0 & 0 & 0 & 0 & 0 & 0 & 0 & 0 & 0 & 0 & 0 & 0 & 0 & 0 & 0 & 0 & 0 & 0 & 0 & 0 \\
\hline$\stackrel{9}{-}$ & 0 & 10 & 0 & 0 & $r$ & 0 & 10 & 0 & - & 0 & 0 & 0 & 0 & 0 & - & 10 & - & 0 & 0 & 10 & - & 0 & 0 & - & 0 & 0 & - & 0 \\
\hline$\stackrel{\infty}{\infty}$ & 0 & $c$ & 10 & 0 & 0 & 0 & 10 & 0 & 0 & & 0 & 0 & 0 & 0 & 0 & 10 & 10 & 0 & 0 & 10 & 0 & 0 & 10 & 0 & 0 & 0 & 0 & 0 \\
\hline$\approx$ & 0 & 10 & 0 & 0 & 0 & 0 & 0 & 0 & 0 & 10 & 0 & 0 & 0 & 0 & 0 & 0 & 0 & 0 & 0 & 0 & 0 & 0 & c & 0 & 0 & 0 & 0 & 0 \\
\hline $\mathscr{0}$ & 0 & 10 & 0 & 0 & 0 & 0 & 10 & 0 & 0 & 0 & 10 & 10 & 0 & 0 & 0 & 0 & 0 & 0 & 0 & 0 & 0 & 0 & c & 10 & 0 & 0 & 0 & 0 \\
\hline$\stackrel{2}{2}$ & 0 & 0 & 0 & 0 & 0 & 0 & 0 & 0 & 0 & 0 & 0 & 0 & 0 & - & 0 & 0 & 0 & 0 & 0 & 0 & 0 & 0 & - & 0 & 0 & 0 & 0 & 0 \\
\hline 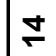 & 0 & 0 & 0 & - & 0 & 0 & - & 0 & 10 & 0 & 0 & - & - & 0 & - & 0 & 0 & 0 & 0 & - & 0 & 0 & 10 & - & - & 0 & - & 0 \\
\hline$m$ & 0 & 0 & 0 & 0 & 0 & D & 0 & 0 & 0 & $c$ & 0 & 0 & 0 & 0 & 0 & 0 & 0 & 0 & 0 & 0 & 0 & 0 & i & 0 & 0 & - & 0 & 0 \\
\hline$\cong$ & 0 & 0 & 0 & 0 & 0 & 0 & 0 & 0 & 0 & 0 & 0 & 0 & 0 & 0 & - & 0 & 0 & 0 & 0 & 0 & 0 & 0 & 0 & 0 & 0 & 0 & - & 0 \\
\hline$\mp$ & 0 & 0 & 0 & 0 & 0 & 0 & 0 & 0 & 0 & 0 & 0 & 0 & 0 & 0 & 0 & 0 & 0 & 0 & 0 & 0 & 0 & 0 & o & 0 & 0 & 0 & 0 & 0 \\
\hline 우 & 0 & 0 & 0 & 0 & 0 & 0 & 0 & 0 & 0 & 0 & 0 & 0 & 0 & 0 & 0 & 0 & 0 & 0 & - & 0 & 0 & 0 & - & 0 & 0 & 0 & 0 & 0 \\
\hline 0 & 10 & 0 & 0 & 0 & 0 & 0 & 0 & 0 & 0 & 10 & 0 & 0 & 0 & 0 & 0 & 0 & 0 & 0 & 0 & 0 & 0 & - & 0 & 0 & 0 & 0 & - & 0 \\
\hline$\infty$ & - & o & 0 & 0 & 0 & 0 & 0 & 0 & 0 & 0 & 0 & 0 & - & 0 & 0 & - & 0 & 0 & 0 & 0 & 0 & - & 10 & 0 & 0 & 0 & 0 & 0 \\
\hline$r$ & 0 & 10 & 0 & 0 & - & 0 & 0 & - & 0 & $c$ & - & - & 0 & 0 & 0 & 0 & 0 & 0 & 0 & 0 & 0 & 0 & c & 0 & 0 & 0 & - & 0 \\
\hline 0 & 0 & 10 & 0 & 0 & 0 & - & 0 & - & 0 & $c$ & 0 & - & 0 & 0 & - & 0 & 0 & 0 & 0 & 0 & - & 0 & c & 0 & 0 & 0 & - & 0 \\
\hline in & 0 & 0 & - & 0 & 0 & 0 & 0 & 0 & 0 & $r$ & 0 & - & 0 & 0 & 0 & 0 & 0 & 0 & 0 & 0 & 0 & 0 & I & o & - & 0 & 0 & 0 \\
\hline$\theta$ & 0 & - & 0 & 0 & 0 & 0 & 0 & - & 0 & 0 & 0 & 0 & 0 & 0 & 0 & 0 & 0 & 0 & 0 & 0 & 0 & 0 & 10 & o & 0 & 0 & 0 & - \\
\hline$m$ & 0 & 10 & 0 & 0 & 0 & 0 & 0 & 0 & 0 & 0 & 0 & - & 0 & 0 & 0 & 0 & 0 & - & 0 & 0 & 0 & 0 & o & 0 & 0 & 0 & - & - \\
\hline N & - & 0 & 0 & 0 & 0 & 10 & 0 & 0 & 0 & $c$ & 0 & - & 0 & 0 & - & 0 & 0 & 0 & 0 & 0 & 0 & 0 & 18 & 0 & 0 & 0 & 0 & 0 \\
\hline$r$ & 0 & 0 & 0 & 0 & 0 & 0 & 10 & 0 & 10 & $10^{\circ}$ & 10 & - & 0 & 0 & 0 & 10 & 10 & 0 & 0 & 10 & 0 & 0 & 10 & 10 & 0 & 0 & 0 & 0 \\
\hline
\end{tabular}

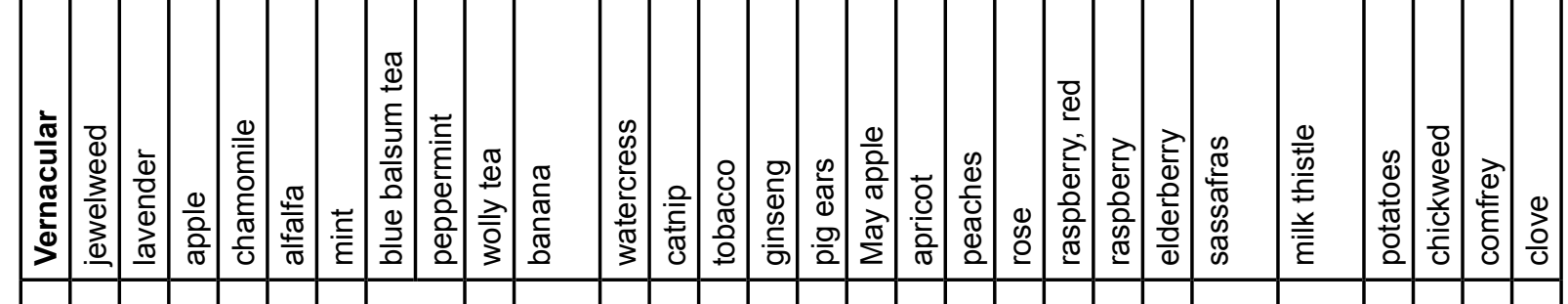
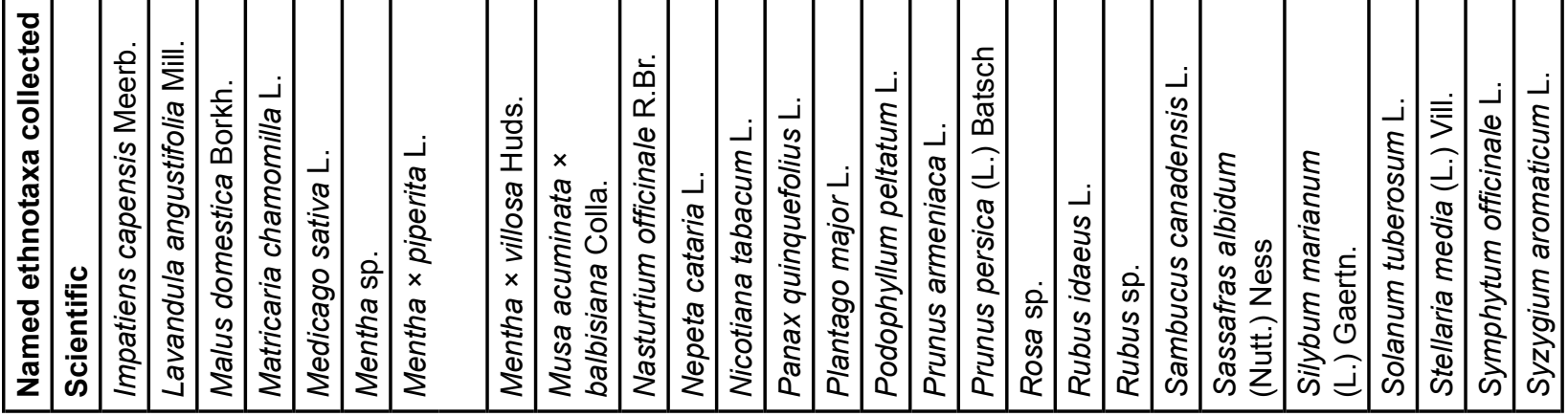


\begin{tabular}{|c|c|c|c|c|c|c|c|c|c|c|c|c|}
\hline & 오 & 0 & 0 & 0 & 0 & 0 & 0 & 0 & 0 & 0 & 0 & 0 \\
\hline & $\stackrel{9}{\circ}$ & 0 & 0 & - & 0 & - & 0 & - & - & - & - & 0 \\
\hline & $\stackrel{\infty}{\sim}$ & 0 & 0 & 0 & 0 & 0 & 0 & 0 & 0 & 0 & 0 & 0 \\
\hline & $\approx$ & 10 & 0 & 10 & 0 & 0 & o & 0 & 0 & 0 & 0 & 0 \\
\hline & 0 & 0 & 0 & 0 & 0 & 0 & 0 & 0 & 0 & 0 & 0 & 0 \\
\hline & 10 & 0 & 0 & 0 & 0 & 0 & 0 & 0 & 0 & 0 & 0 & 0 \\
\hline & \pm & - & 0 & - & 0 & 0 & 0 & 0 & 0 & 0 & - & - \\
\hline & $m$ & - & 0 & 0 & o & 0 & 0 & 0 & 0 & 0 & 0 & 0 \\
\hline & ₹ & 0 & 0 & 10 & 0 & 0 & 0 & 0 & 0 & 0 & 0 & 0 \\
\hline & $\mp$ & 0 & 0 & 0 & 0 & 0 & 0 & 0 & 0 & 0 & 0 & 0 \\
\hline & 으 & 0 & 0 & 0 & 0 & 0 & 0 & 0 & 0 & 0 & 0 & 0 \\
\hline & 0 & - & 0 & - & 0 & 0 & - & 10 & 0 & 0 & 10 & 0 \\
\hline & $\infty$ & 0 & 0 & 0 & - & 0 & 0 & 0 & 0 & 0 & 0 & 0 \\
\hline & 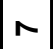 & - & - & 0 & 0 & 0 & 0 & 0 & 0 & 0 & 0 & 0 \\
\hline & 0 & - & 0 & 0 & 0 & 0 & 0 & 0 & 0 & 0 & 0 & 0 \\
\hline & in & 0 & 0 & 0 & o & 0 & - & 0 & 0 & 0 & 0 & 0 \\
\hline & 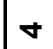 & 0 & 0 & 0 & 0 & 0 & 0 & 0 & 0 & 0 & - & 0 \\
\hline & $m$ & 0 & 0 & 0 & 0 & 0 & 0 & 0 & 0 & - & - & 0 \\
\hline & N & 10 & 0 & 0 & 0 & 0 & 10 & 0 & 0 & 10 & 10 & 0 \\
\hline & $1-$ & 10 & 0 & 10 & 0 & 0 & 10 & 0 & 0 & 10 & 10 & 0 \\
\hline & 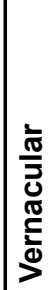 & 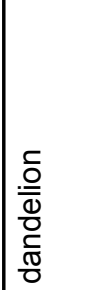 & 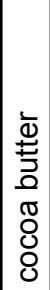 & 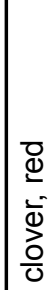 & \begin{tabular}{|l}
$\bar{\Phi}$ \\
$\overline{0}$ \\
$\overline{0}$
\end{tabular} & 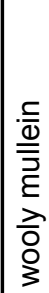 & $\mid \begin{array}{l}0 \\
0 \\
0 \\
0 \\
0 \\
0 \\
\end{array}$ & 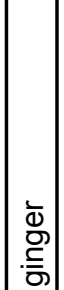 & 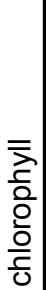 & 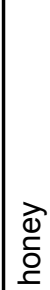 & 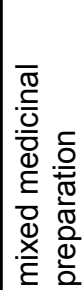 & 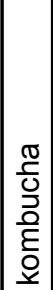 \\
\hline 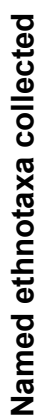 & 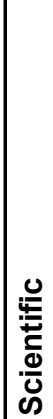 & 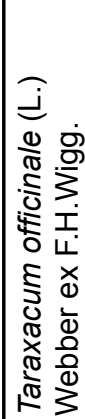 & 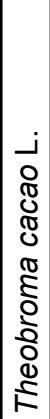 & 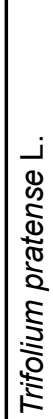 & 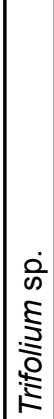 & 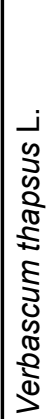 & 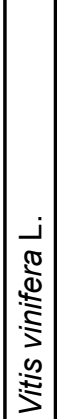 & 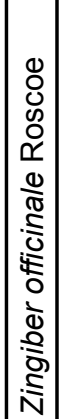 & 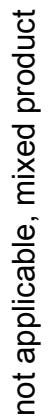 & & & 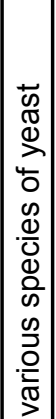 \\
\hline
\end{tabular}

